Article

\title{
Optimally Tuned Interleaved Luo Converter for PV Array Fed BLDC Motor Driven Centrifugal Pumps Using Whale Optimization Algorithm-A Resilient Solution for Powering Agricultural Loads
}

\author{
A. Darcy Gnana Jegha ${ }^{1}$, M.S.P. Subathra ${ }^{1}$, Nallapaneni Manoj Kumar ${ }^{2, *(D)}$ and \\ Aritra Ghosh 3,4,*(D) \\ 1 Department of Electrical and Electronics Engineering, School of Engineering and Technology, \\ Karunya Institute of Technology and Sciences, Coimbatore, Tamil Nadu 641114, India; \\ darcyjegha@gmail.com (A.D.G.J.); subathra@karunya.edu (M.S.P.S.) \\ 2 School of Energy and Environment, City University of Hong Kong, Hong Kong, China \\ 3 Environment and Sustainability Institute, University of Exeter, Penryn, Cornwall TR10 9FE, UK \\ 4 College of Engineering, Mathematics and Physical Sciences, Renewable Energy, University of Exeter, \\ Cornwall TR10 9FE, UK \\ * Correspondence: mnallapan2-c@my.cityu.edu.hk (N.M.K.); a.ghosh@exeter.ac.uk (A.G.)
}

Received: 14 July 2020; Accepted: 1 September 2020; Published: 4 September 2020

check for updates

\begin{abstract}
The use of brushless direct current (BLDC) motors are gaining much prominence in water pumping systems (WPS), especially for agricultural purposes. In most cases, the BLDC based WPS is powered using electricity from the grid, which is vulnerable to disruptive events causing a resilience problem. However, to avoid the resilience issue, grid-interactive solar photovoltaics (PV) are being used, and this is due to the increased penetration of distributed generation sources into the grid. In these systems, based on the inherent nature of solar PV, power converters are preferred, and as a result, problems like switching losses and maintaining steady-state voltages are commonly seen. In this paper, a framework of PV powered WPS with scope for optimizing controller parameters is proposed to avoid the above-raised issues. Based on the proposed framework, the overall structure of the PV powered WPS is modeled, designed, and analyzed. In the proposed system, the power output from solar PV is fed to the BLDC motor and the grid. If any problem arises in obtaining the power from solar PV, grid-interaction helps to run the motor at required speeds making the WPS resilient to unexpected disruptions and vice versa. For retrieving the generated power from PV array, a positive interleaved Luo converter (I-Luo) is used, which boosts the output with minimum switching losses. To maintain the steady-state voltage at the output of the I-Luo converter, a proportional-integral (PI) controller whose parameters are tuned by whale optimization algorithm (WOA) is used. This voltage is fetched to the BLDC motor via a 3-phase (3- $\Phi$ ) inverter and then to the grid via a single-phase $(1-\Phi)$ inverter. The overall system is simulated and experimentally validated, with a detailed analysis of the observed results. The results include the various performance characteristics of the solar PV, converter, and BLDC motor. Besides, by using the field-programmable gate array (FPGA) based SPARTAN6E controller, the performance of the I-Luo is examined experimentally.
\end{abstract}

Keywords: photovoltaic array; solar applications in agriculture; agrivoltaics; water pumping system; BLDC based water pumps; PV based agro water pumps; PV powered water pumps; Luo converter; whale optimization; optimal tuning of control parameters; FPGA based SPARTAN6E controller; minimum switching losses; steady-state voltages; maximum peak shoot problem; centrifugal water pump 


\section{Introduction}

In the modern world, more or less, every industrial sector (e.g., agriculture, food processing, water distribution, infrastructure, transportation, etc.) relies on energy [1]. Among all these sectors, with the new developments and advances, the agriculture sector can be considered as one of the emerging energy-intensive sectors. In almost all countries, we could see that most of the agricultural activities that happened to be fruitful are with the help of energy systems, either grid or off-grid powered [2]. Speaking from a developing country perspective (e.g., in countries like India, Brazil, China, Argentina, etc.), most of the agricultural activities are grid-dependent, especially the water pumping systems (WPS). However, many still use diesel-powered WPS too, and the reasons for this are the limited power supply timings, power outages, and in some cases, lack of power infrastructure for powering these loads. Thus, raising the questions on the resilience of the WPS that are primarily used in agricultural purposes, and this becomes more critical in countries where they have a high dependency on oil imports. Due to the supply chain and other disruptive scenarios, they may face an energy crisis, ultimately leading to the resilience problem. The most commonly suggested solution for this is the use of a renewable-based power supply system, especially the solar photovoltaic (PV) powered systems [3]. On the other hand, the use of solar PV systems for different application is gaining its prominence in most of the countries irrespective of a developed or developing economy. At the same time, an innovative approach, i.e., the use of brushless direct current (BLDC) motors, are handled for the efficient use of energy from solar PV [4,5].

In literature, there exist many studies highlighting the operation and benefits of BLDC based WPS. Some even stressed more on integrating renewable energies for BLDC motors along with the roles of power converters. Youssef (2014), [6] proposed a simple design procedure to realize a cost-effective BLDC drive for water pump application where the torque ripple issues that were existed in the previous design approaches are solved, thereby an effective BLDC model is proposed for the WPS. Along with the motor, the control voltage is dropped-in leading to the elimination of the necessity of a battery. In contrast to the existing methods for WPS, the proposed method reduces both the current and the voltage drop of the rectified voltage. Shukla and Singh (2018) [7] proposed a reduced current sensor based solar PV fed sensorless induction motor drive for WPS; thereby, a cost-effective drive system is realized with less number of sensors. The variation in the performance parameters is noticed thoroughly as the robustness of the system depends on its stability. However, when a decrease in solar insolation occurs, the whole system performance gets affected, allowing us to think of redesigning the system from a resiliency point of view. It is believed that grid-interactive solar PV would be a more promising solution. In literature, many have studied resilience problems and have suggested solutions in the context of residential electricity users [8], island electrification [9], and powering primary health care centers [10].

In the same way, researchers have started exploring grid interfaced PV powered WPS. In a recent study by Murshid and Singh (2019) [11], a utility grid-interactive solar PV powered WPS using permanent magnet synchronous (PMSM) drive is proposed with improved power quality (PQ) performance for operation under abnormal grid conditions. For achieving the improved $P Q$, a hybrid control structure is used to continue the water flow effectively, regardless of any grid abnormalities, and the variation in solar insolation. Here, it is better to eliminate the direct current (DC)-offset and the dominant lower harmonics for better results, and the same is resolved with the hybrid control structure, thereby delivering enhanced filtering. However, the sudden increase in solar insolation may lead to an increase in the output current value of the solar PV array, which demands the need for the current limiting controller. Errouissi et al. [12] presented an experimental validation of a novel proportional-integral (PI) speed controller for alternating current (AC) motor drives with improved transient performances. In their study, the current limits speed and stableness of the closed-loop control are discussed to understand the controller behavior. From their investigation, it is clear that the novel PI controller achieves better performance, and no overshoot is observed even when a chance of saturation pertains to the exhibit. Even though the system is free from disturbances, there is a steep decrease in the speed reference, which in turn causes an increase in the integrator 
output. Chincholkar and Chan (2015), [13] demonstrated a comparative study of current-mode controllers for the positive output elementary Luo converter via state-space and frequency response approaches. This comparison is made based on dynamic performances, speed, and robustness. As per the investigation, the bode plot was plotted; however, they couldn't identify the instability that occurred, causing the system to fall into an unstable state. The comparing modules are not favorable in case of continuous conduction mode operation. In another study, boost and buck-boost converters have been used, and these converters helped in boosting the output voltages. Even though it boosts the output voltage high, it suffered from the problem of complicated feedback loop compensation. Hence, to overcome this, a positive interleaved Luo converter (I-Luo) is utilized. This I-Luo converter helps to gain high output and also works well in performing soft-switching action. A maximum power point tracking (MPPT) scheme, such includes perturb and observe, fuzzy logic, incremental conductance, etc. has been used to control the converters to operate the PV array at its maximum power point (MPP) [14-16]. However, here, maintaining the constant output voltage from the power converter is very critical. In conventional systems, they utilized a PI controller to sustain a steady-state mode [17-21]. The main aspect to be concerned with the PI controller is the peak overshoot problem. To address this, an approach has to be developed that allows limiting maximum peak overshoot. When the output shoots beyond the desired value, the issue of peak overshoot arises and leads to time consumption of retrieving the constant voltage [22,23]. For this purpose, in literature, a novel optimization approaches have been adopted $[18,19]$. However, in most of the approaches, the desired value is fixed, and it does not exaggerate over the fixed value, and it almost produces the output without time delay [24]. Thus, the produced DC output voltage from the converter is then fed to the BLDC motor and the grid through a corresponding 3-phase (3- $\Phi)$ and 1-phase (1- $\Phi)$ inverters. Overall, here, the PV array powered BLDC motors drive the centrifugal pump serving the purpose of agricultural water demands.

From the above literature study, it is understood that based on the inherent nature of the solar PV operation, and as per the adopted power electronic system, the PV powered BLDC motor driven WPS had suffered from problems like switching losses and maintaining steady-state voltages. In addition, to these, the inherent nature of solar PV and the weather impacts on its performance have left questions on the resilience of the WPS. In literature, it is mentioned that the optimal tuning of controller parameters would be a possible solution to overcome the problem of peak overshoot. Hence, to address all the above-highlighted problems, a framework of PV powered BLDC motor driven WPS for agricultural purposes with scope for optimizing controller parameters is proposed. Based on the proposed framework, the overall structure of the PV powered WPS is modeled, designed, and analyzed in this paper. The key contributions of this work are as follows:

- To address the issue of resilient operation, a grid-interactive PV powered BLDC motor driven WPS is proposed. This proposed system follows the bidirectional power flow technique. During daylight hours, the power retrieved from PV is high enough to drive the motor pump. Meanwhile, the fetched power from $\mathrm{PV}$ is high; it can be served to nearby agro-processing industries and domestic purposes. However, at night time, the solar PV is not able to generate power. In that case, the power in the grid will be sufficiently used to drive the motor pump. Thus, the resilience operation of WPS is achieved.

- In the proposed system for retrieving the generated power from PV array, a positive I-Luo converter is used, which boosts the output with minimum switching losses.

- To maintain the steady-state voltage at the output of the I-Luo converter, a PI controller whose parameters are tuned by whale optimization algorithm (WOA) is used.

In this study, the overall system is simulated, and the results of the proposed system are observed, which include the performance characteristics of the solar PV, converter, and BLDC motor. Besides, by using the field-programmable gate array (FPGA) based SPARTAN6E controller, the performance of the interleaved Luo converter is examined experimentally. 
The article is structured in four different sections; Section 2 presents the overall conceptual framework and a brief description of the proposed system. In Section 3, modeling of the proposed system, along with the optimization procedure, is presented. In Section 4 , simulation and experimental results are discussed. Finally, the conclusions were drawn and presented in Section 5.

\section{Conceptual Framework and Description of the Water Pumping System}

The proposed system is aimed to meet the requirement of agricultural loads by ensuring the resilience operation of WPS. The system is designed considering various components, and these include a PV array, I-Luo converter, PI controller, 1- $\Phi$ and 3- $\Phi$ voltage source inverters (VSI), BLDC motor, grid, and the centrifugal pump. The conceptual circuit diagram of the proposed grid-interactive solar PV powered BLDC motor driven WPS is shown in Figure 1.

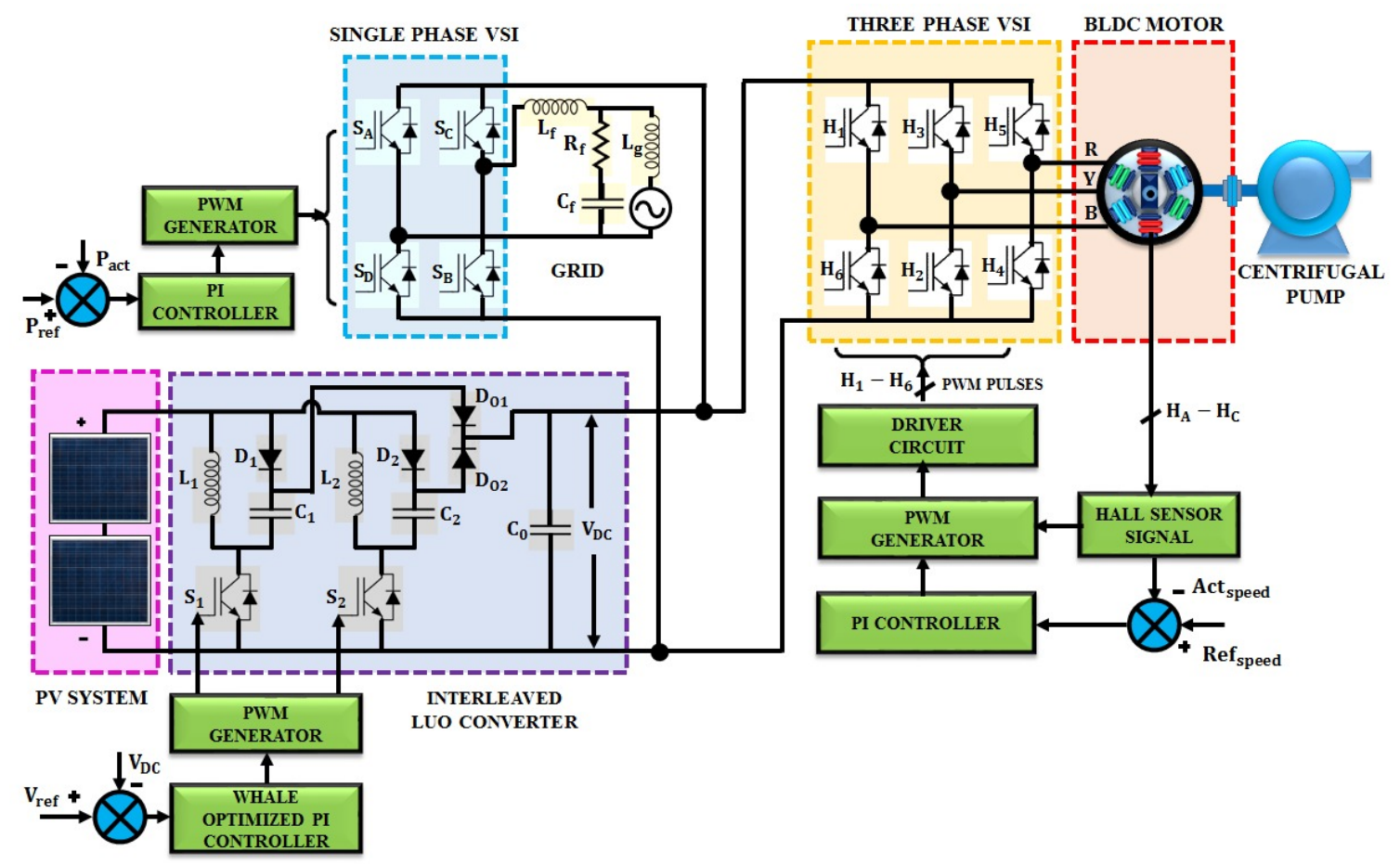

Figure 1. Circuit of the proposed grid-interactive solar photovoltaic powered brushless direct current motor-driven water pumping system.

Here, the solar PV array acts as a power generating unit. The power fetched from solar PV is fed to the I-Luo converter, which is further supplied to the BLDC motor coupled to the centrifugal water pump via the VSI. The benefit of using the I-Luo converter is, it minimizes the switching losses and increases the stability of output voltage using the optimization approach. When analogizing with the conventional PI controller, the whale optimized PI controller has a good scope in getting rid of the maximum peak overshoot problem. Using an optimally tuned PI controller, the converter reaches its steady-state without exaggerating the fixed value. The maximum peak overshoot problem is eliminated, and fixed voltage is fed to the BLDC motor via VSI to run the motor pump at high speed, and the benefit of this 3- $\Phi$ VSI is, it allows the bidirectional flow of power. It is to be noted that the power rating of solar PV is maintained above the maximum rated capacity of the motor so that the additional power can be fed to the utility grid via 1- $\Phi$ VSI, which can be used by nearby food processing industries and domestic consumers. When the solar PV output power is insufficient to run the motor, the grid power is used by the BLDC motor through the 1- $\Phi$ VSI. The 1- $\Phi$ inverter acts as a bidirectional converter, which means the power is made to flow in any direction depending on the terminal voltage. During the unavailability of PV power, the BLDC motor consumes power from 
the grid via the VSI. PI controller performs the switching function of the VSI. The difference between the actual capacity of the motor and the reference power is given to the PI controller to generate the pulse-width modulation (PWM) pulses for the switches. The design and implementation of the proposed system are explained elaborately in the upcoming sections.

\section{Modeling of the Proposed Water Pumping System for Agricultural Application}

In this section, the proposed grid-interactive solar PV powered BLDC motor driven WPS is modeled considering its individual components. In addition, the optimization procedure and whale optimization algorithm implementation for tuning PI controller parameters is also discussed.

\subsection{Design of Solar Photovoltaic Array}

The equivalent circuit of the solar PV system is represented in Figure 2, as shown below. From Figure 2, it is understood that the output parameters of the solar PV cell depend upon the input parameters. Here, $I_{P V}$ is the input current of the photovoltaic cell; $I_{D}$ is the current flowing through the diode; $R_{p}$ and $R_{s}$ are the series and parallel resistance; $I$ and $V$ are the output current and voltage [16].

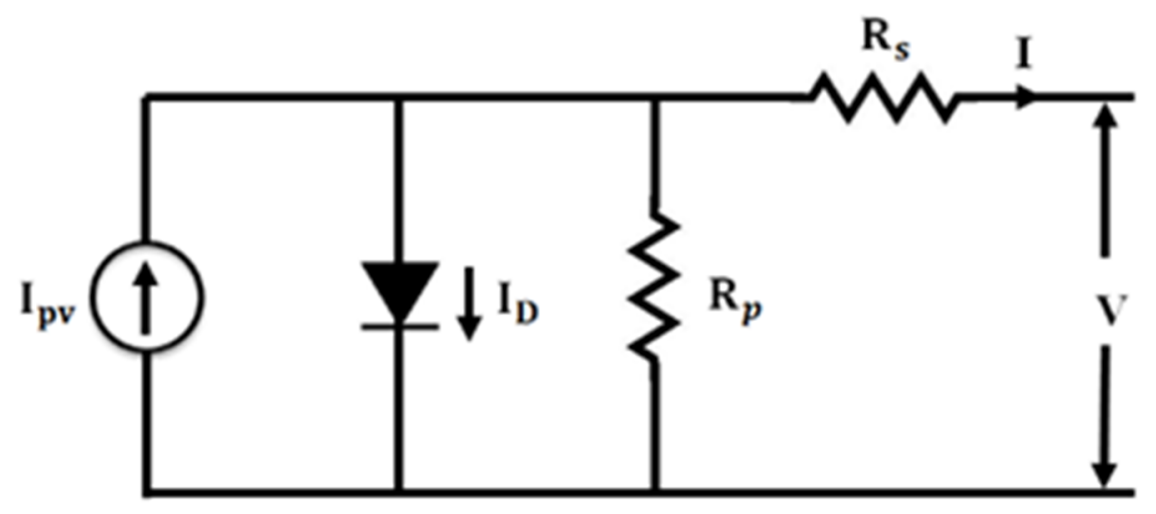

Figure 2. The equivalent circuit of solar photovoltaic cell.

The output current of the solar PV cell is shown in Equations (1) and (2), depends on input cell current, thermal voltage, the output voltage of solar PV cell, and resistance of the PV cell [16].

$$
\begin{gathered}
I=I_{P V \text { cell }}-I_{\text {scell }}\left[\exp \frac{(q v)}{\alpha K T}-1\right] \\
I=I_{P V}-I_{o}\left[\exp \frac{\left(v+R_{s} . I\right) q}{\alpha V_{k}}-1\right]-\frac{\left(v+R_{s} \cdot I\right)}{R_{p}}
\end{gathered}
$$

where, $I_{P V \text { cell }}$ represent the solar PV cell current; $I_{\text {scell }}$ or $I_{0}$ is the PV cells saturation current; $I$ and $v$ output current and voltage; thermal voltage, $V_{k}=\frac{K T}{q} ; q$ is $1.6 \times 10^{-19} \mathrm{C}$ charge of the electron; $K$ is Boltzman constant; $T$ ambient temperature; $\alpha$ is ideality factor; $R_{S}$ and $R_{p}$ are the series and parallel resistance, respectively.

The represented current output in Equation (2) is for a single PV cell. This can be re-written for the PV module configuration, as shown in Equation (3). In general, this is based on the $N_{s}$ i.e., the number of PV cells connected in series [25].

$$
I=I_{P V}-I_{o}\left[\exp \frac{\left(v+R_{s} I\right) q}{\alpha K T \cdot N_{s}}-1\right]-\frac{\left(v+R_{s} . I\right)}{R_{p}}
$$

From Equation (3), it is understood that the current to voltage (I-V) relation of the solar PV array is non-linear, and this is due to the change in incident solar insolation and the rise in PV array temperature. Hence, it is essential to look into the optimum operating region to extricate maximum 
power output from the solar PV array. The maximum power is obtained from the solar PV array if the array resistance is the same as the load resistance. The I-Luo converter connects the solar PV array with the BLDC motor driven WPS so that the resistance of BLDC is matched with the array resistance by varying the duty ratio of the converter. The power generated from the solar PV array is given as $P_{m p}=1.5 \mathrm{~kW}$, which was designed for the proposed WPS. The specification of the PV modules that are used to design the $1.5 \mathrm{~kW}$ PV array is given in Table 1. The solar PV array is estimated to work at $1000 \mathrm{w} / \mathrm{m}^{2}$, and in the simulation modeling, a fixed value of solar irradiance is maintained.

Table 1. Specification of the solar photovoltaic module.

\begin{tabular}{cc}
\hline Parameters. & Values with Unit \\
\hline Peak power $\left(P_{m p}\right)$ & $100 \mathrm{~W}$ \\
No. of modules in the PV array & 15 \\
Open circuit voltage $\left(V_{o c}\right)$ & $22.68 \mathrm{~V}$ \\
Short circuit current $\left(I_{s c}\right)$ & $5.86 \mathrm{~A}$ \\
Peak power voltage $\left(V_{m p}\right)$ & $18.75 \mathrm{~V}$ \\
Peak power current $\left(I_{m p}\right)$ & $5.42 \mathrm{~A}$ \\
Number of series-connected cells $\left(N_{s}\right)$ & 36 \\
\hline
\end{tabular}

To perform the proposed work in a successful and efficient way, solar PV array, I-Luo converter, and BLDC motor are clearly framed. The retrieved output power from the PV panel is delivered to the positive I-LUO converter that is discussed in Section 3.2.

\subsection{Design of Proposed Positive Interleaved Luo (I-Luo) Converter}

The I-Luo converter helps to attain an output of high voltage transfer gain and low ripple. The circuit of the proposed converter is given in Figure 3. The performance of the proposed I-Luo converter under altering illumination is evaluated in Simulink based simulation. The comparative analysis of the performance of the proposed I-Luo converter with different topologies is discussed in Appendix A [25].

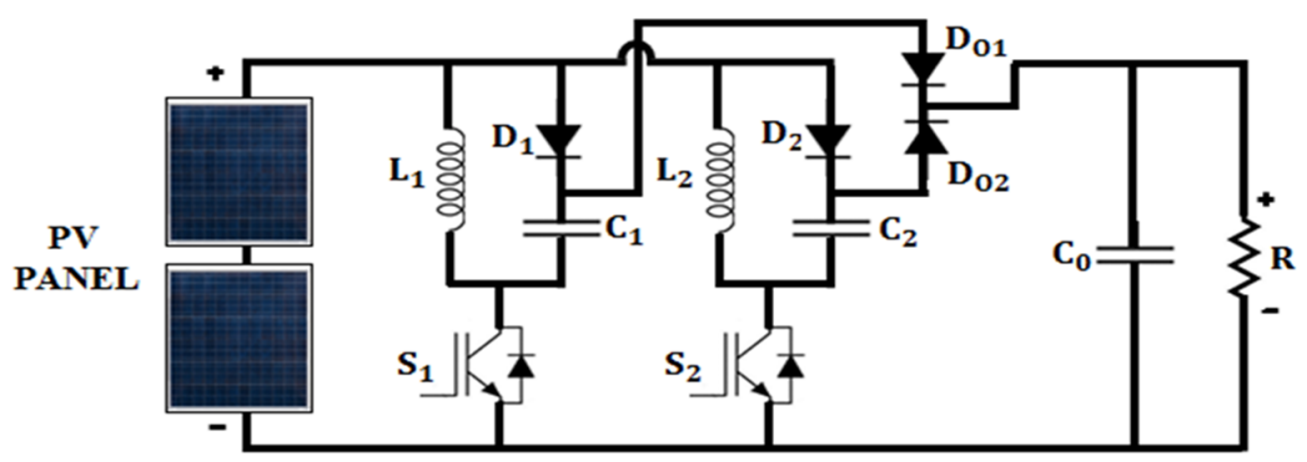

Figure 3. Circuit of the proposed interleaved Luo converter.

The output voltage of the proposed converter, i.e., $V_{o}$ is expressed in Equation (4);

$$
V_{o}=3 \frac{2-d}{1-d} V_{P V}
$$

where $d$ is the duty cycle of the converter, $V_{P V}$ is the output voltage of the PV array.

A high operating cycle may require if the output voltage of the PV is at a minimum. The I-Luo converter consists of an inductor, capacitor, and power switches. By making use of inductor, only $40 \%$ 
ripple current be permitted, as shown in Equation (5). Therefore, the problem of gaining the output ripple current can be minimized.

$$
\Delta I_{L}=I_{L} \times 40 \%=I_{o} \frac{\left(V_{o} \times 40 \%\right)}{V_{P V}(\min )}
$$

From Equation (6), the values of inductances $L_{1}$ and $L_{2}$ can be computed as:

$$
L_{1}, L_{2}=\frac{V_{P V}(\mathrm{~min})}{\Delta I_{L} \times f_{s w}} \cdot d m a
$$

where dmax is the maximum duty cycle of the pulse applied to the I-Luo converter

The input root mean square (RMS) value of the current can be obtained using Equation (7):

$$
I_{\text {Cin }}(r m s)=\frac{\Delta I_{L}}{\sqrt{12}}
$$

When a switch is in the ON position, the inductor gets electrified, and the output current is directly delivered to the output capacitor, as shown in Equation (8).

$$
I_{C o}(r m s)=I_{o} \sqrt{\frac{V_{D C}+V_{D}}{V_{P V}(\min )}}
$$

where $V_{D C}$ is the output voltage of the converter and $V_{D}$ is the voltage drop across diode $D_{1}$ and $D_{01}$

The resultant capacitance value can be obtained by using Equation (9);

$$
C_{o}=\frac{I_{0} \times d}{V_{\text {ripple }} X_{0.5} X_{f s w}}
$$

where $d$ is the duty cycle of the PWM pulse, $X_{0.5}$ and $X_{f s w}$ define the impedance at $50 \%$ duty cycle and the switching frequency. The designed numerical values of the I-Luo converter are given in the Appendix A.

\subsubsection{State-Space Representation}

The state-space approach is better when analogizing with the transfer approach. For performing an efficient computational process, it should be consociated with matrix/vector modeling. It provides an error-free response and performs its function when the power switch $S_{1}$ and $S_{2}$ are kept in ON and OFF positions, respectively. In matrix form, it is represented as per Equations (10) and (11),

$$
\begin{aligned}
& X=A X+B U \\
& Y=C X+D U
\end{aligned}
$$

where, $X$ is a state variable; $U$ is input vector; $A, B, C$, and $D$ represent the state, input, output, and transition matrices; $Y$ is the output variable.

Here, a set of state equations are represented in terms of matrices $A$ and $B$, and by using the state variables, a set of outputs is defined. The state variables of the proposed converter are represented as per Equation (12).

$$
X_{1}=i_{L 1} ; X_{2}=i_{L 2} ; X_{3}=V_{c 1} ; X_{4}=V_{c 2}
$$


Equation (13) is possible during the mode of ON position of switch $S_{1}$ :

$$
A_{1}=\left[\begin{array}{cccc}
0 & 0 & 0 & 0 \\
0 & 0 & \frac{1}{L_{2}} & 0 \\
0 & -\frac{1}{c_{1}} & 0 & 0 \\
0 & 0 & 0 & -\frac{1}{R C_{2}}
\end{array}\right] \quad B_{1}=\left[\begin{array}{c}
\frac{1}{L_{1}} \\
0 \\
0 \\
0
\end{array}\right]
$$

Equation (14) is possible during the mode of ON position of switch $S_{2}$ :

$$
A_{2}=\left[\begin{array}{cccc}
0 & 0 & -\frac{1}{L_{1}} & -\frac{1}{L_{2}} \\
0 & 0 & 0 & -\frac{1}{L_{2}} \\
-\frac{1}{C_{1}} & 0 & 0 & 0 \\
\frac{1}{C_{1}} & \frac{1}{C_{2}} & 0 & -\frac{1}{R C_{2}}
\end{array}\right] \quad B_{2}=\left[\begin{array}{c}
\frac{1}{L_{2}} \\
0 \\
0 \\
0
\end{array}\right]
$$

The average can be computed by using Equation (15) as follows, and here $d$ is the duty cycle of the PWM pulse.

$$
X=\left[A_{1}(1-d)+A_{2} d+\left[B_{1}(1-d)+B_{2} D\right] . U\right]
$$

\subsubsection{Working of Proposed Interleaved Luo Converter}

The working of the I-Luo converter and its performance in the course of turn ON and turn OFF operation are discussed in this section. Figure $4 \mathrm{a}-\mathrm{c}$ describe in detail the operation of I-Luo converter. The I-Luo converter is mainly meant to ensure the steady-state voltage and current. The components of the converter are represented as follows, power switch $S_{1}$ and $S_{2}$, inductance $L_{1}$ and $L_{2}$, and switched capacitor $C_{1}$ and $C_{2}$.

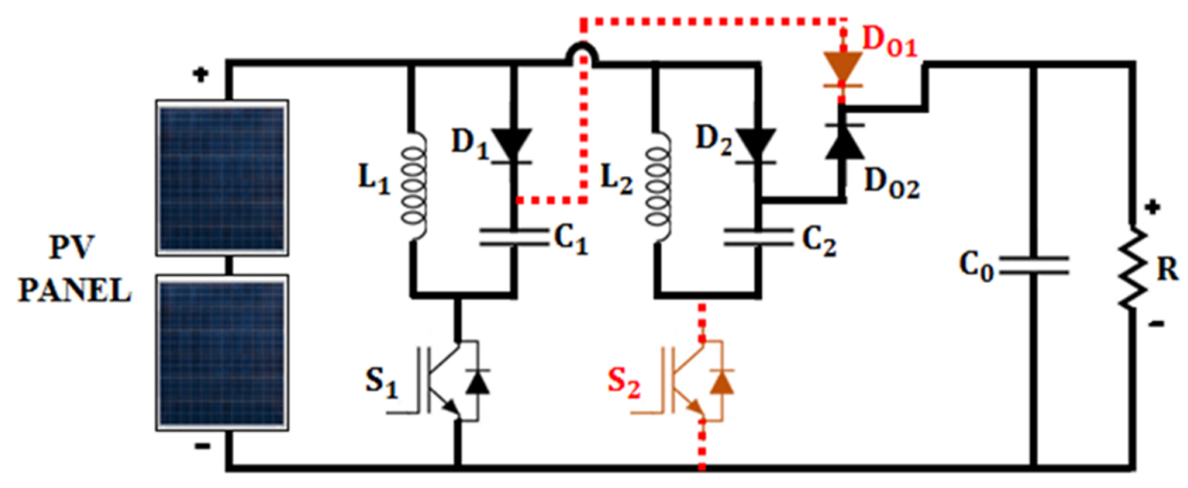

(a)

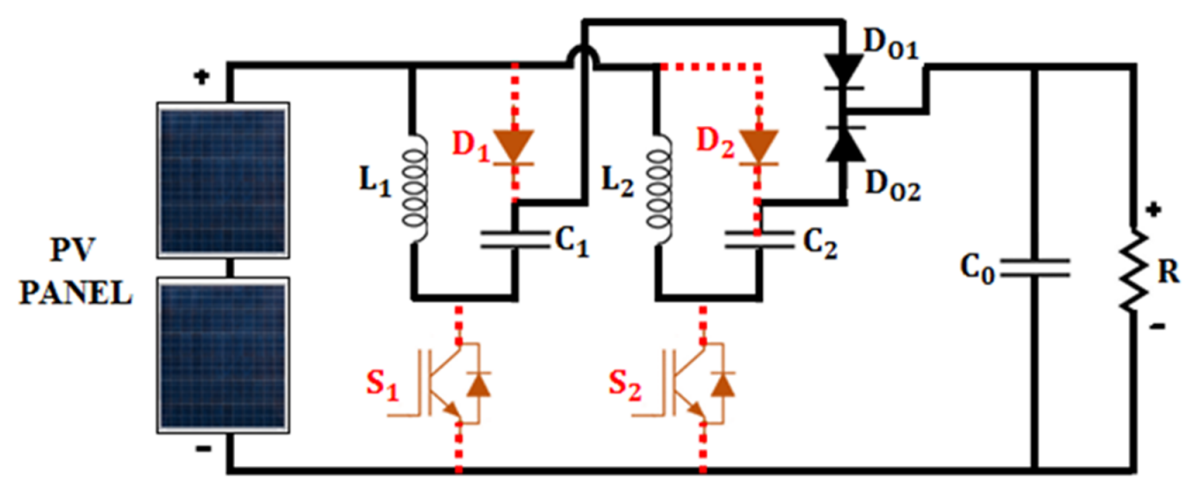

(b)

Figure 4. Cont. 


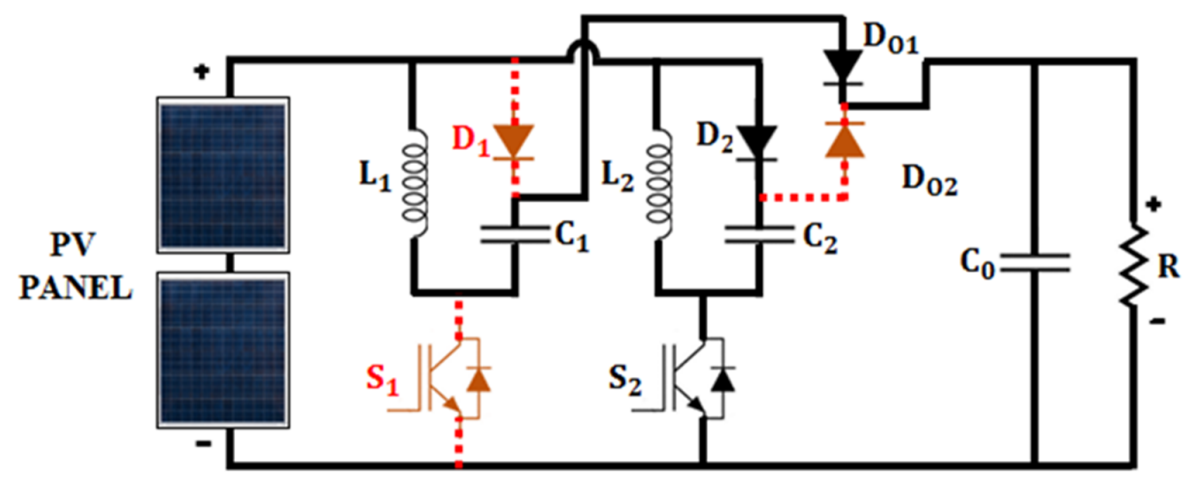

(c)

Figure 4. Operation of the Luo converter in: (a) Phase-1; (b) Phases-2 and 4; (c) Phase-3.

In Phase-1, initially, power switch $S_{1}$ is in the position of OFF mode, and $S_{2}$ is in ON mode; hence diode $D_{01}$ is forward biased, and $D_{02}$ is reverse biased. The inductor $L_{1}$ and $L_{2}$ are permitted to allow the current to flow through the load, and the voltage across capacitor $C_{1}$ and $C_{2}$ get charged from the gained PV supply. Two diodes are used in this proposed converter. It acts as a one-way switch for current. Here diode $D_{1}$ act as forward biased, and it permits the current to flow through the load, and diode $D_{2}$ restricts the current flowing from the other side.

In Phase-2, both power switches, $S_{1}$ and $S_{2}$, are found to be in ON mode; hence, diodes $D_{01}$ and $D_{02}$ are reverse biased. The inductor in this phase, $L_{1}, L_{2}$, gets charged by the PV supply. Both diode $D_{1}$ and $D_{2}$ are found to be reversely biased in Phase- 2 .

In Phase-3, the power switch $S_{1}$ is in the position of the ON mode, and $S_{2}$ is in the OFF mode. Hence diode $D_{01}$ is reverse biased, and $D_{02}$ is forward biased. The inductor $L_{1}$ gets charged, and $L_{2}$ gets released to flow through the load. Diode $D_{2}$ permits the current to flow in the direction of load and diode $D_{1}$ restricts.

In Phase-4, both power switches are found to be in the mode of OFF position, and diodes $D_{01}$ and $D_{02}$ are said to be forward biased. The inductor which was present in Phase-4 gets released through the load, and the diode is in forward bias.

The comparison of different Luo converter topologies based on the number of components involved and gain achieved by them are given in Tables 2 and 3. The elementary, self-lift, re-lift, and triple-lift are the topologies that are considered for comparison in the above tables [22]. In addition, the interleaved configurations of boost, single-ended primary-inductor converter (SEPIC), and Luo converters utilized for comparing the voltage gain and efficiency [23].

Table 2. Comparison of proposed Luo converter components with different Luo converter structures.

\begin{tabular}{cccc}
\hline LUO Converter Circuit & No. of Inductors & No. of Diodes & No. of Switches \\
\hline Elementary & 2 & 1 & 1 \\
Self-lift & 2 & 2 & 1 \\
Re-lift & 3 & 3 & 2 \\
Triple-lift & 4 & 4 & 2 \\
Proposed interleaved & 2 & 4 & 2 \\
\hline
\end{tabular}

Table 3. Proposed Luo converter output voltage gain comparison with different Luo converter structures.

\begin{tabular}{|c|c|c|c|c|}
\hline \multirow{2}{*}{ LUO Converter Circuit } & \multirow{2}{*}{$I_{0}$} & \multirow{2}{*}{$V_{0}$} & \multicolumn{2}{|c|}{$V p v=80 \mathrm{~V}$} \\
\hline & & & $d=0.5$ & $d=0.75$ \\
\hline Elementary & $I_{0=} \frac{1-d}{d} I_{p v}$ & $V_{0=} \frac{d}{1-d} V_{p v}$ & 160 & 210 \\
\hline Self lift & $I_{0=}(1-d) I_{p v}$ & $V_{0=} \frac{1}{1-d} V_{p v}$ & 180 & 240 \\
\hline
\end{tabular}


Table 3. Cont.

\begin{tabular}{ccccc}
\hline & & & \multicolumn{2}{c}{$\boldsymbol{V} \boldsymbol{p v}=\mathbf{8 0 ~ V}$} \\
\cline { 4 - 5 } LUO Converter Circuit & $\boldsymbol{I}_{\mathbf{0}}$ & $\boldsymbol{V}_{\mathbf{0}}$ & $\boldsymbol{d}=\mathbf{0 . 5}$ & $\boldsymbol{d}=\mathbf{0 . 7 5}$ \\
\hline Re lift & $I_{0=\frac{1-d}{2}} I_{p v}$ & $V_{0=\frac{2}{1-d}} V_{p v}$ & 190 & 310 \\
Triple lift & $I_{0=\frac{1-d}{3}} I_{p v}$ & $V_{0=\frac{3}{1-d}} V_{p v}$ & 210 & 410 \\
Proposed interleaved & $I_{0=\frac{1-d}{3(2-\mathrm{d})} I_{p v}}$ & $V_{0=3 \frac{2-d}{1-d} V_{p v}}$ & 230 & 600 \\
\hline
\end{tabular}

\subsection{Whale Optimization Algorithm for Tuning Controller Parameters}

In this study, a PI controller and whose parameters are optimally tuned by Whale optimization algorithm (WOA) is used. The flowchart of the whale optimization-based PI controller is shown in Figure 5. WOA is a new optimization technique, and this algorithm consists of two stages. Encircling prey and spiral updating position are implemented in the first stage. Searching for prey is done randomly in the second stage. The whales recognize the location of prey after that it encircles them. Initially, the position of the optimum design in the search is not known, and therefore, the current best candidate solution is assumed as the target prey or near to the optimum. Then the remaining search agents also change their location and try to give the best search agents. Here, the winding air pocket net caring move is numerically demonstrated so as to perform optimization. In addition, a brief theory of WOA is given in Appendix A.

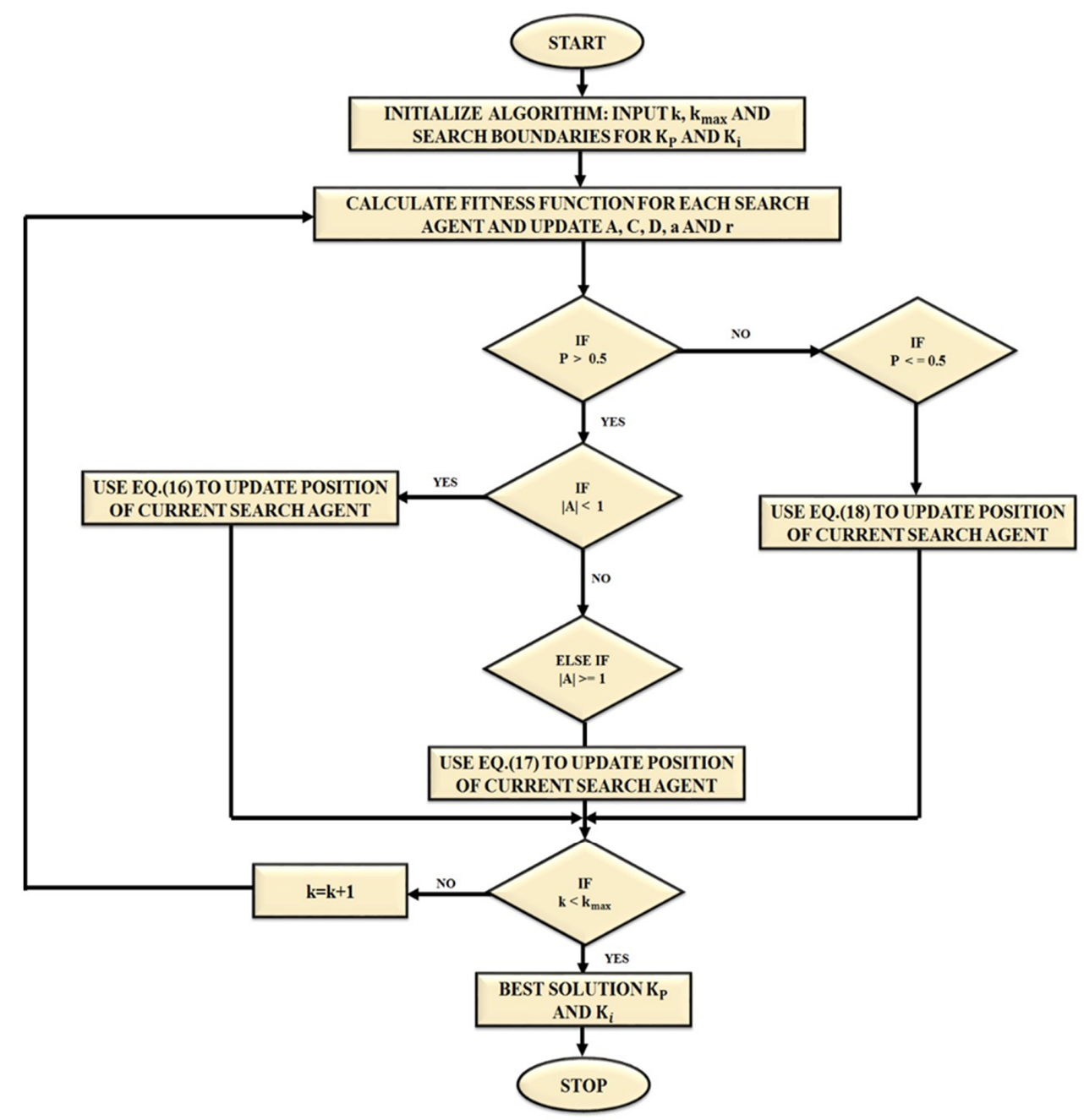

Figure 5. Flowchart for tuning the controller parameters using a whale optimization algorithm. 
The characteristic of a whale is mathematically modeled as per Equations (16) and (17);

$$
\begin{gathered}
\vec{D}=\left|\vec{C} \cdot \vec{X}^{*}(k)-\vec{X}(k)\right| \\
\vec{X}(k+1)=\overrightarrow{X^{*}}(k)-\vec{A} \cdot \vec{D}
\end{gathered}
$$

where $k$ is present iteration; $\vec{A}$ and $\vec{C}$ denote the vector coefficients; $\overrightarrow{X^{*}}(k)$ represents the whales earlier best location at iteration $k ; \vec{X}(k+1)$ represents whale's current position; $\vec{D}$ represents the distance between whale and prey. The vector coefficients $\vec{A}$ and $\vec{C}$ are computed as per Equations (18) and (19);

$$
\begin{gathered}
\vec{A}=2 \vec{a} \cdot \vec{r}-\vec{a} \\
\vec{C}=2 \cdot \vec{r}
\end{gathered}
$$

Over the iteration process, the value of $\vec{a}$ minimizes from 2 to $0, \vec{r}$ is an arbitrary variable that ranges from 0 to 1 . By adjusting the values of $\vec{A}$ and $\vec{C}$ different places around the best search agents can be reached with respect to the current position. The encircling mechanism is performed by reducing the value of $\vec{a}$, thereby the oscillation in $\vec{A}$ is reduced. The search agent can be placed between the actual position of the agent and position of the existing best agent by setting random values of $\vec{A}$ in the range $[-1,1] . \vec{C}$ helps in putting some extra weight on the search agent to emphasize or de-emphasize based on their random values.

The MPPT act as an objective function, and it is computed as per Equation (20);

$$
\begin{gathered}
\text { Maximize } P(d), \\
\text { Expose to } d_{\min } \leq d \geq d_{\max }
\end{gathered}
$$

$d_{\min }$ and $d_{\max }$ are the minimum (0.1) and maximum (0.9) duty cycles, respectively.

Here, the whale optimization helps to get rid of maximum peak overshoot. By taking the population of whales as the operating ratio, it minimizes the balanced state oscillation. Whale optimization helps to enhance the system efficiency as well as reduces the power loss [26]. To control the PWM pulses using the controller, it is mathematically computed as per Equation (21),

$$
d_{i}(k+1)=d_{i}(k)-A . D
$$

The objective function is evaluated using Equation (22);

$$
P\left(d_{i}^{k}\right)>P\left(d_{i}^{k^{-1}}\right)
$$

As we knew that the solar PV power is based on the climatic condition and solar irradiation, the output power may vary. Therefore, to obtain the steady-state output, the variation in solar PV output is computed using Equation (23).

$$
\frac{p^{k}-p^{k-1}}{p^{k}} \geq 0.1
$$

By varying the PI controller parameters $k p$ and $k i$ using WOA, a reference signal is produced. This reference signal is analogized with the carrier signal to produce PWM pulses. The produced pulse is given to the positive I-Luo converter. The comparison of conventional and optimized PI controllers is given in Appendix A. 


\subsection{Operation of Brushless Direct Current Motor}

The BLDC motor is said to be a synchronous motor. This motor gets electrified by a DC electric source through an inverter, which further generates an AC signal to run the motor. Two significant components of this motor are stator and rotor. The rotor which was present in the BLDC motor is a permanent magnet [27]. The rotor and stator are represented in Figure 6.

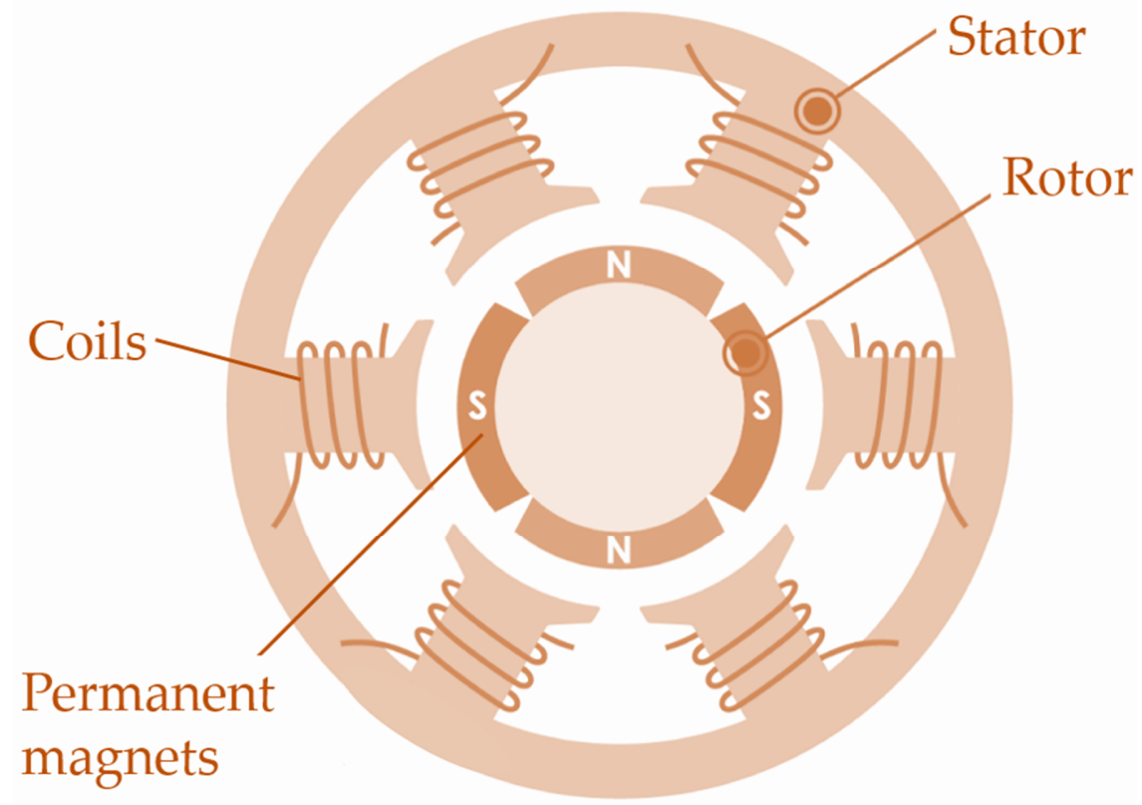

Figure 6. Rotor and stator of the brushless direct current motor.

The operation of BLDC is dependent on the interaction of force that happens between rotor and electromagnet. In order to know the position of the rotor, the Hall sensor is used. By using this BLDC motor, the speed range is higher, and the higher efficiency is achieved [27]. The mathematical Equation of BLDC motor is presented in the form of a matrix as shown in Equation (24):

$$
\left[\begin{array}{l}
V_{a} \\
V_{b} \\
V_{c}
\end{array}\right]=\mathrm{R}\left[\begin{array}{lll}
1 & 0 & 0 \\
0 & 1 & 0 \\
0 & 0 & 1
\end{array}\right]\left[\begin{array}{c}
i_{a} \\
i_{b} \\
i_{c}
\end{array}\right]+\left[\begin{array}{ccccc}
L & - & M & 0 & 0 \\
0 & L & - & M & 0 \\
0 & 0 & L & - & M
\end{array}\right] \frac{d}{d t}\left[\begin{array}{c}
i_{a} \\
i_{b} \\
i_{c}
\end{array}\right]+\left[\begin{array}{c}
E_{a} \\
E_{b} \\
E_{c}
\end{array}\right]
$$

where, $V_{a}, V_{b}, V_{c}$ are the phase voltages; $i_{a}, i_{b}, i_{c}$ are the phase currents; $L$ and $M$ are the self and mutual inductance of the coil; $E_{a}, E_{b}, E_{c}$ are the back emfs; and $R$ is the resistance. The computational representation of current in each stage of BLDC motor is expressed in Equations (25)-(27).

$$
\begin{aligned}
& \frac{d_{i a}}{d t}=\frac{1}{L-M}\left(v_{a}-E_{a}-R i_{a}\right) \\
& \frac{d i_{b}}{d t}=\frac{1}{L-M}\left(V_{b}-E_{b}-R i_{b}\right) \\
& \frac{d i_{c}}{d t}=\frac{1}{L-M}\left(V_{C}-E_{c}-R i_{c}\right)
\end{aligned}
$$

By performing Kirchhoff's voltage law, the voltage applied to the BLDC motor is expressed using Equation (28):

$$
V_{d}=R_{a} i+L_{a} \frac{d i}{d t}+E
$$


The mathematical torque computation is expressed using Equations (29) and (30),

$$
\begin{gathered}
T=J \frac{d \omega_{m}}{d t}+B \omega_{m}+T_{L} \\
T=K_{t} I \\
I=\frac{J}{K_{t}} \frac{d \omega_{m}}{d t}+\frac{B}{K_{t}} \omega_{m}
\end{gathered}
$$

By substituting Equation (31) into (28), we obtain Equation (32):

$$
V_{d}=\frac{L_{a}}{K_{t}} \frac{J d^{2} \omega_{m}}{d t}+\frac{\left(R_{a} J+L_{a} B\right)}{K_{t}} \frac{d \omega_{m}}{d t}+\frac{\left(R_{a} J+K_{e} K_{t}\right)}{K_{t}}
$$

Applying the Laplace transform, the above Equation (32) is transformed as Equation (33);

$$
\frac{\omega_{m}(s)}{V_{d}(s)}=\frac{K_{t}}{L_{a} J S^{2}+\left(R_{a} J+L_{a} B\right) S+\left(R_{a} B+K_{e} K_{t}\right)}
$$

As $L_{a} B$ and $R_{a} B$ is very small when it is compared with $K_{e} k_{t}$, as shown in Equation (34);

$$
\frac{\omega_{m}(s)}{V_{d}(s)}=\frac{k_{t}}{L_{a} J s^{2}+\left(R_{a} J\right) S+\left(K_{e} K_{t}\right)}
$$

The transfer function of the BLDC motor is computed using Equation (35):

$$
\frac{\omega_{m}(s)}{V_{d}(s)}=\frac{1 / K_{e}}{\tau_{e} \tau_{m} s^{2}+\tau_{m} s+1}
$$

where the mechanical time constant $\tau_{m}=\frac{R_{a} J}{K_{e} K_{t}}$; electrical time constant $\tau_{e}=L_{a} / R_{a}$.

The final function is computed using Equation (36);

$$
G_{i}(s)=\frac{14.993}{1.24 e^{-2} s^{2}+10.293 e^{-3} s+1}
$$

\subsection{Design of Voltage Source Inverter}

For single-phase voltage source inverter, the current expression is derived as below shown in Equation (37) [18].

$$
i_{d c_{2}}=\left(2 D_{2}-1\right) i_{v s c}
$$

The value of inductance through which current is flowing is computed as per Equation (38);

$$
L_{f} \frac{d i_{v s c}}{d t}=\left(2 D_{2}-1\right) V_{D C}-v_{s}
$$

where $D_{2}$ is the duty cycle of the inverter; $i_{v s c}$ is the current flowing through the inverter; $V_{D C}$ is the DC-link voltage; $v_{S}$ is the AC voltage fed to the grid.

\section{Results and Discussion}

In this section, the overall system is simulated and experimentally validated. The observed and validated results include the various performance characteristics of the solar PV, converter, and BLDC motor. Besides, by using the field-programmable gate array (FPGA) based SPARTAN6E controller, the performance of the interleaved Luo converter is examined experimentally. 


\subsection{Simulation Results}

Under the different operating conditions, the scrutinization of the proposed system is performed through a simulated result using MATLAB Simulink. The implemented system is validated by measuring the performances at initial, running, and steady-state. The parameters of BLDC motor are such as speed, and voltage values are considered as speed: $3000 \mathrm{rpm} @ 270 \mathrm{~V}$, Voltage: $68 \mathrm{~V} / \mathrm{rpm}$. Due to the variation in climatic conditions and temperature, it ranges from $960-1000 \mathrm{w} / \mathrm{m}^{2}$. Therefore, it should be maintained continuously at $1000 \mathrm{w} / \mathrm{m}^{2}$. The operation of the motor is validated using a moment of force, power, speed, and electromotive force. The monitored parameters from the solar PV powered BLDC motor driven WPS are shown in Figure 7. Here, Figure 7a, presents performance parameters of the solar PV array, Figure $7 \mathrm{~b}$ presents the performance parameters of the BLDC motor, and Figure 7c presents the I-Luo converter and grid parameters.
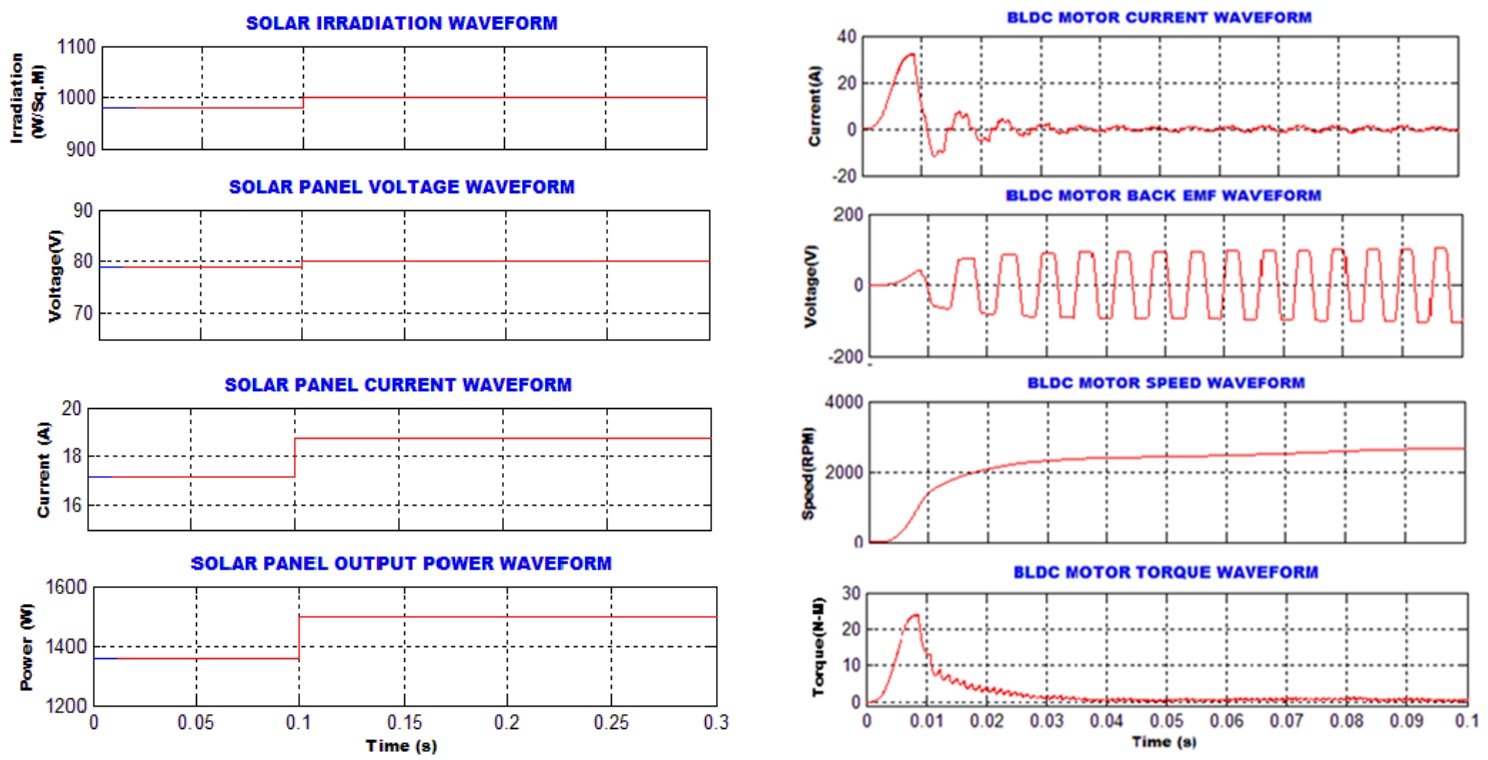

(a)

(b)

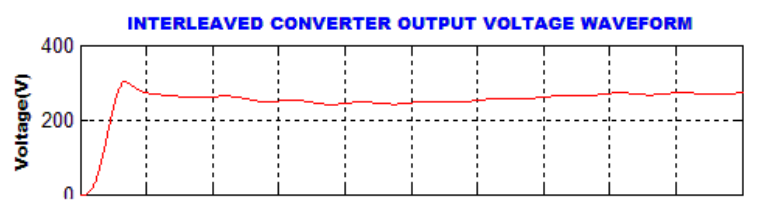

GRID OUTPUT VOLTAGE WAVEFORM
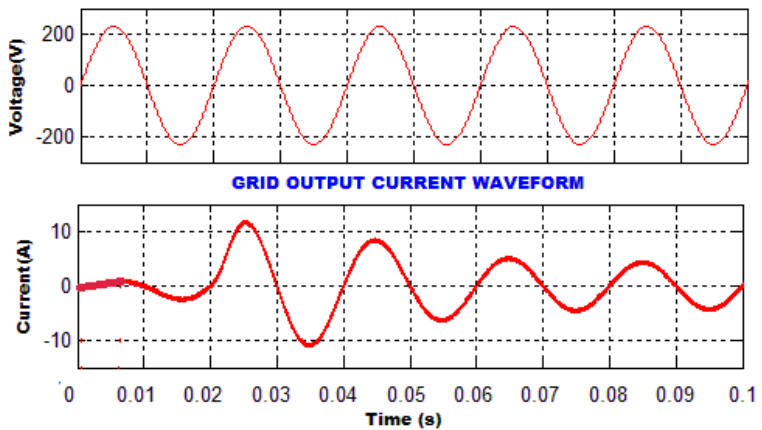

(c)

Figure 7. Electrical performance parameters: (a) solar photovoltaic array; (b) the brushless direct current motor; (c) interleaved Luo converter and grid. 
The solar PV array output of the proposed system shown in Figure 7a represents waveforms of solar irradiance level, panel voltage, current, and power. Though the torque value exaggerates in the course of initialization, it should be sustained steadily at $2 \mathrm{Nm}$. To reduce the disturbances on switching and other powered devices, a positive I-Luo converter performs its operation at continuous current (CC) mode. The dynamic performance of the system is evaluated by changing the solar irradiation at $0.1 \mathrm{~s}$, and the output characteristics of the converter and grid current are measured corresponding to this variation. As shown in Figure 7a, the output power from the solar PV array is changed at the same instant at which change in insolation occurs. The beginning operation of the proposed positive I-Luo converter operates at $960 \mathrm{w} / \mathrm{m}^{2}$ is represented in Figure 7c. The converter output will take some time to reach and settle at the rated value. This time delay causes the grid current to be nil initially and gradually increases to the maximum value. The BLDC motor parameters, such as current, back electromagnetic force (EMF), speed, and torque, are shown in Figure $7 \mathrm{~b}$. The higher starting current and torque of BLDC motor causes the motor to start for low speed. As the current amplitude is reduced, the motor attains a steady speed. The current consumed by the motor during running time is considerably low. A maximum speed of nearly $2895 \mathrm{rpm}$ is achieved very quickly to attain steady operation.

In Figure 8, the performance parameters under the dynamic operating modes of the BLDC motor and the I-Luo converter and grid are shown. Figure 8a shows the torque, speed, current, and EMF waveforms of BLDC motor during running state. It is found that there is no oscillation in speed; also, ripple quantity is minimum. The power quality of the grid is preserved by applying a steady DC voltage to the inverter. To maintain the output voltage at a steady-state position, whale optimization is performed to get rid of the problem of maximum peak overshoot. To track the rotor position of the motor, hall sensors is utilized. Although there is a variation in load, the proposed converter sustains the steady-state DC voltage. The system seems to attain a stable operating region, as seen in Figure $8 \mathrm{~b}$. The grid voltage and current become pure sinusoidal without oscillation in amplitude, and the converter output voltage is also stable with fixed magnitude.
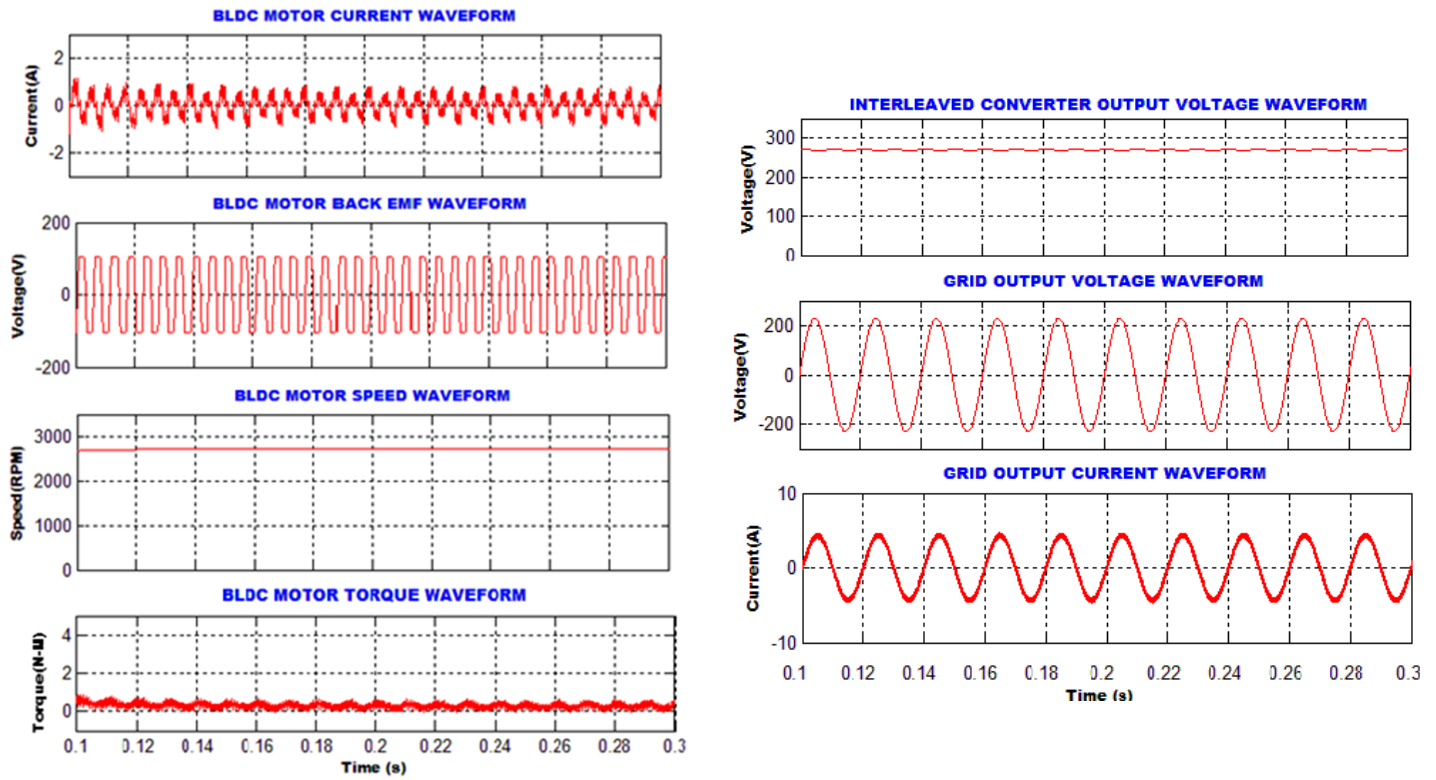

(a)

(b)

Figure 8. Performance parameters under the dynamic operating modes of the: (a) the brushless direct current motor; (b) interleaved Luo converter and grid.

To maintain a steady-state speed without any oscillation even after applying a load, whale optimization is adopted. Initially, the motor is started without any load, and after $0.25 \mathrm{~s}$ 
a load of $2 \mathrm{Nm}$ is applied. In Figure 9, the variation in the performance parameters after applying a load of $2 \mathrm{Nm}$ is shown. This dynamic state of the BLDC motor is depicted in Figure 9a. Practically, the motor will take some time to respond for this change in load (i.e., from no load to a load of $2 \mathrm{Nm}$ ). With this load, the current and proportional torque value of the BLDC motor is also increased. However, the dynamic performance of the motor does not get altered, and the speed is maintained at a fixed value. Figure $9 \mathrm{~b}$ reveals the dynamic performance (i.e., running with load) of the converter and grid is shown. Thus, it is proved that the proposed converter is robust against change in solar insolation and load and giving satisfactory performance both at the starting and running time by maintaining constant DC-link voltage and sinusoidal grid voltage and current.
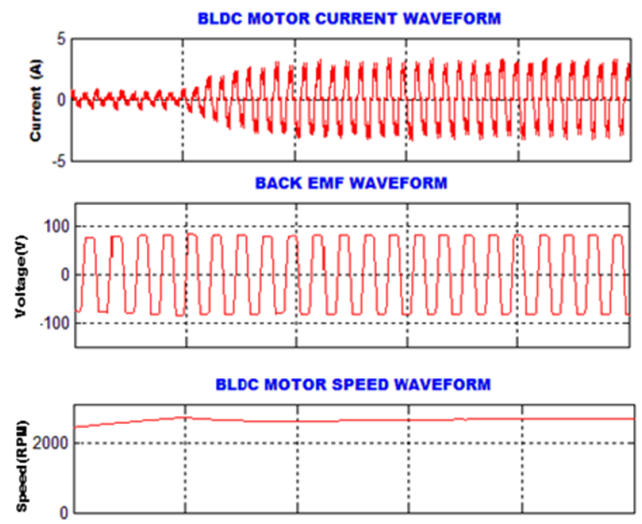

BLDC MOTOR TORQUE WAVEFORM

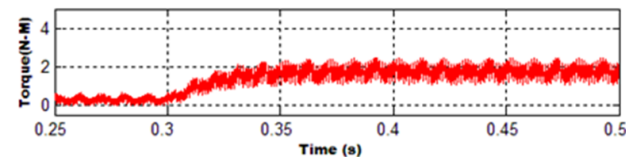

(a)
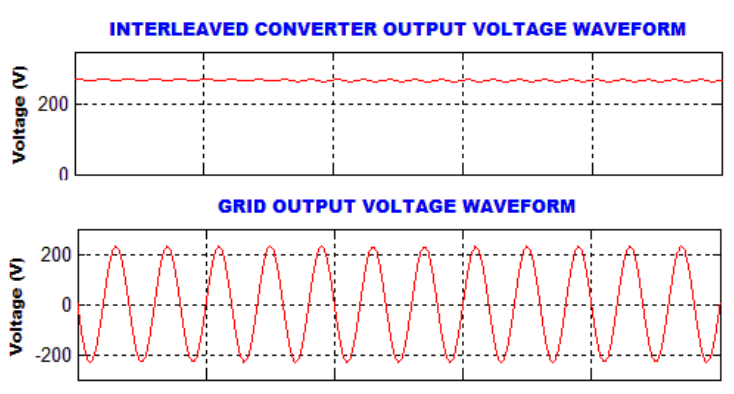

GRID OUTPUT CURRENT WAVEFORM

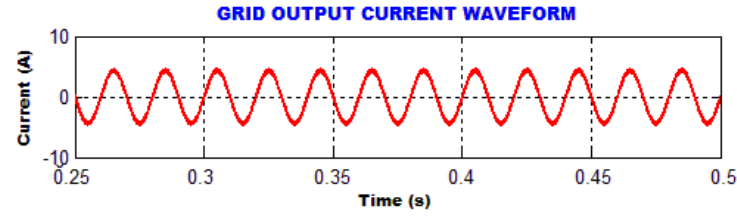

(b)

Figure 9. Performance after applying a load of $2 \mathrm{Nm}$ : (a) the brushless direct current motor; (b) the interleaved Luo converter and grid.

In this study, we measured total harmonic distortion (THD) to understand the overall effectiveness of the system, see Figure 10. In Figure 10a,b, the THD value of grid current with conventional and optimized PI controllers with WOA are shown, respectively. Since the grid current THD is within the Institute of Electrical and Electronics Engineers (IEEE) standard, the proposed system is proved to be effective and suitably can replace all the existing drives of water pump applications. Thus, the system can deliver harmonics free ac current to the motor pump even when there is no PV input or input with oscillation.

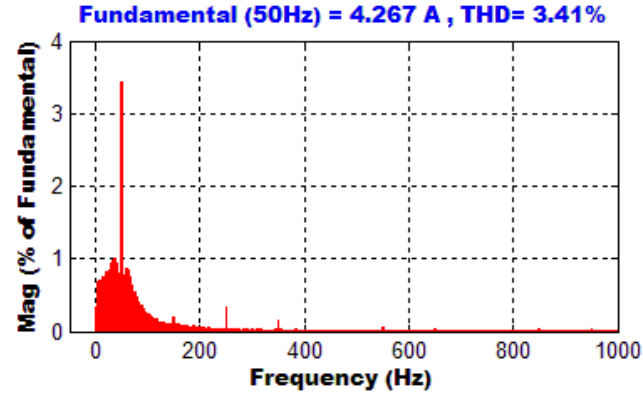

(a)

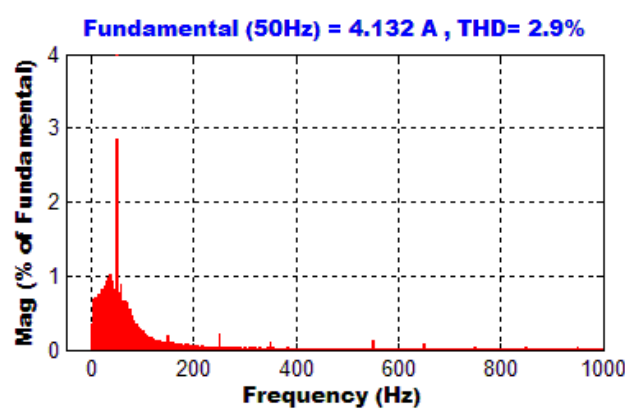

(b)

Figure 10. The total harmonic distortion: (a) grid current total harmonic distortion (THD) waveform with the conventional proportional-integral (PI) controller; (b) grid current THD with whale optimized PI controller. 


\subsection{Results from the Experimental Validation}

In this section, the experimental performance of the proposed system is discussed. The different performance of solar PV array, positive I-Luo converter, and BLDC motor-driven centrifugal pump are verified on an implemented prototype of the proposed system (see Figure 11).

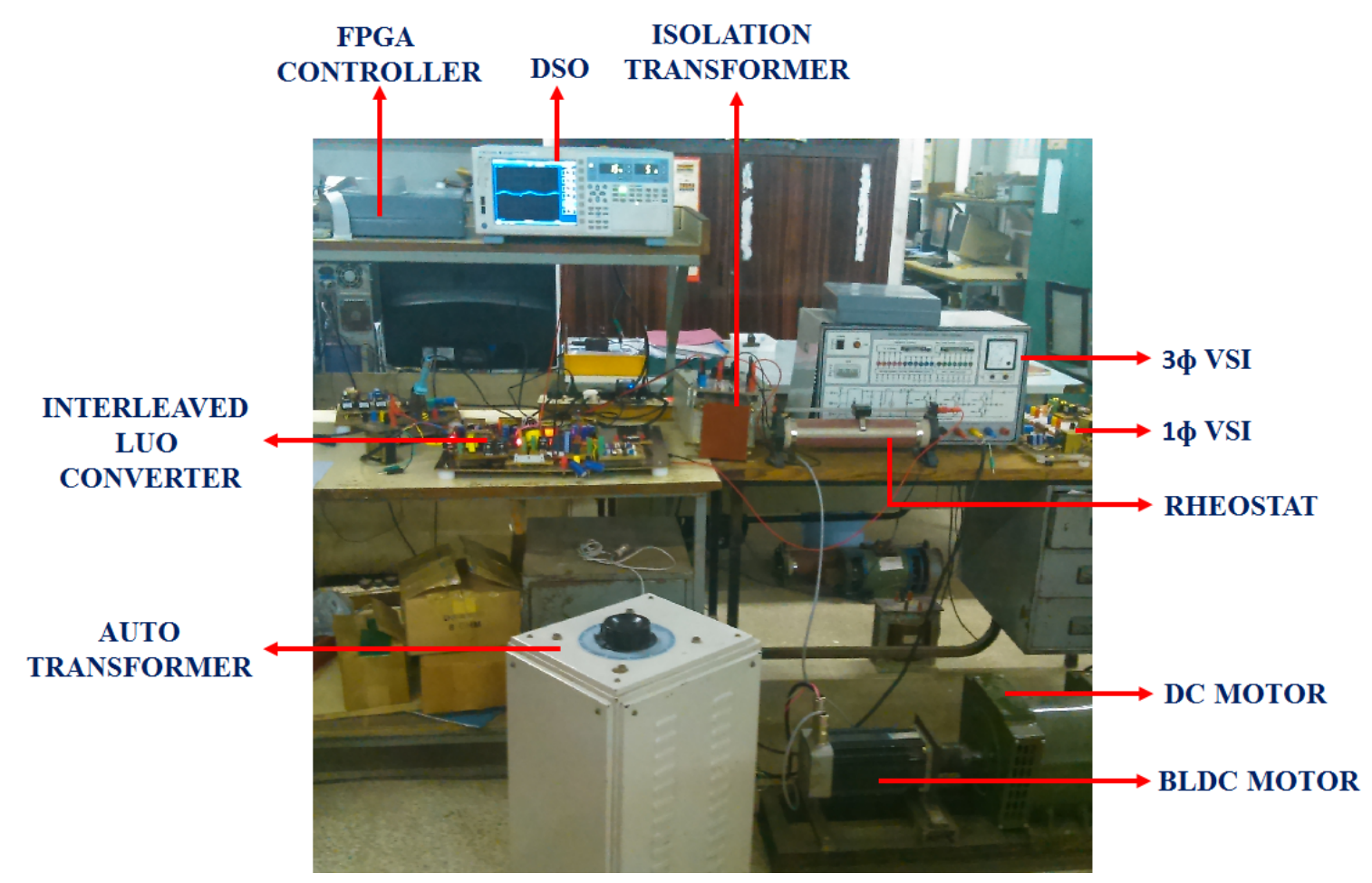

Figure 11. The experimental setup of the proposed system.

In the experimental setup, the motor pump is replaced by the DC generator, whose impedance is resistive. This loading effect of BLDC motor is analogous to an electrified motor pump, and it possesses a constant relationship between moment and speed. The FPGA based SPARTAN6E is an incorporated circuit that comprises of interior equipment sections with programmable interconnections that changes the switching sequences of our system. The FPGA can be programmed at any time, permitting the controller to oblige design changes or help other applications during its lifetime. Nowadays, FPGA based SPARTAN6E becomes the heart of all modern electrical and power circuits whose switching frequency can be varied from $10 \mathrm{kHz}$ to even $100 \mathrm{kHz}$. The optimized PI controller logic is implemented in the FPGA based SPARTAN6E board to develop the hardware setup of the system. The controller produces pulses for the converter at different cycles, depending on the objective function.

As the solar irradiance is changing from $960-1000 \mathrm{w} / \mathrm{m}^{2}$, the power output from the solar PV array also varies from $1.3 \mathrm{~kW}$ to $1.5 \mathrm{~kW}$, and this variation is shown clearly in Figure 12 . The related electrical performance parameters for solar PV array-like solar irradiation, voltage, and current are shown in Figure 12a-c, respectively. Whale optimization helps to get steady output and also eliminates maximum peak overshoot problems. From this, we can clearly understand that although there is a change in climatic condition and solar irradiation, the output voltage gain is maintained in a balanced mode, and also current ripple is minimized. 


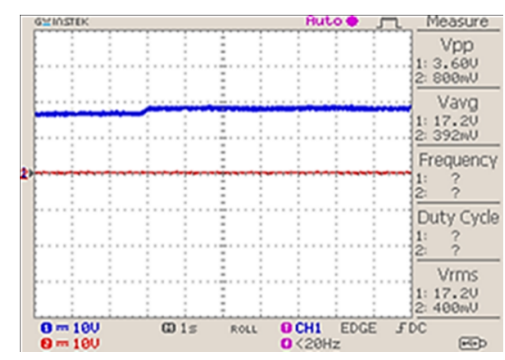

(a)

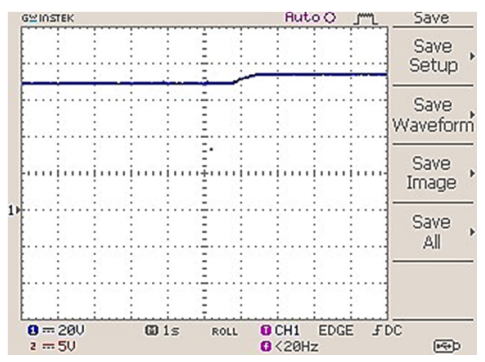

(b)

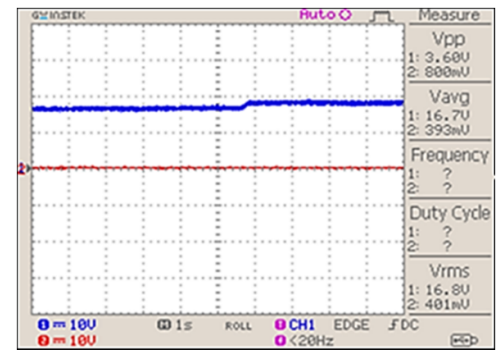

(c)

Figure 12. The variation in performance parameters at the photovoltaics (PV) array side: (a) the incident irradiation on the photovoltaic array; (b) the output voltage; (c) the output current.

The experimental verification of the balanced state of the proposed positive I-Luo converter is shown in Figure 13. The variation in I-Luo converter output voltage is depicted in Figure 13a,b, respectively, which consists of waveforms to show the initial and running performance. In this proposed work, the positive I-Luo converter performs its operation in CC mode to get maximum current output. During the time of running the motor pump, a high ripple gets generated because BLDC motor takes minimum time to attain the considered speed. As the load changes, there is a small exaggeration in photovoltaic current at the starting time and settled to a fixed value for a motor speed of $3000 \mathrm{rpm}$.

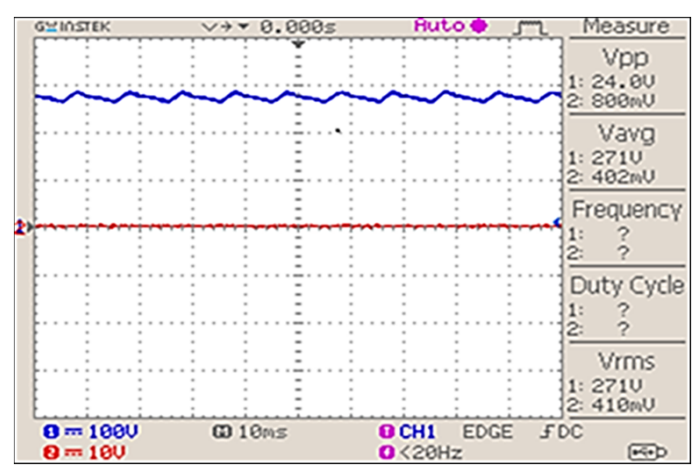

(a)

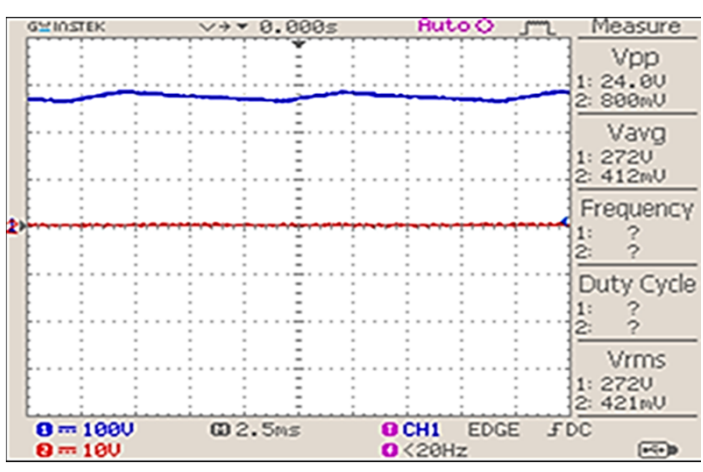

(b)

Figure 13. The observed output voltage of the interleaved Luo converter at (a) the initial time and (b) running time.

The grid voltage and current are shown in Figures 14 and 15 have no oscillations or dip in magnitude. In addition, a sinusoidal waveform is maintained all over the operation period. From Figure 14a,b and Figure 15a,b it clearly indicates that in the course of beginning and execution time, there is no variation in the voltage and current in the grid though there is a change in load and solar insolation. Thus, a balanced mode is maintained in the grid.

In a steady-state mode, the DC-link voltage was maintained. After applying a load of $2 \mathrm{Nm}$, there was an improvement in gaining the gradual speed of the motor pump. The expected rated speed was achieved at a voltage of $270 \mathrm{~V}$ with a 0.67 duty cycle and by providing a demanded amount of torque. High and steady speed was thus achieved with the proposed system. The current generated in the BLDC motor is shown in Figure 16a. The steady speed attained in BLDC motor when experimented with BLDC motor is shown in Figure 16b. 


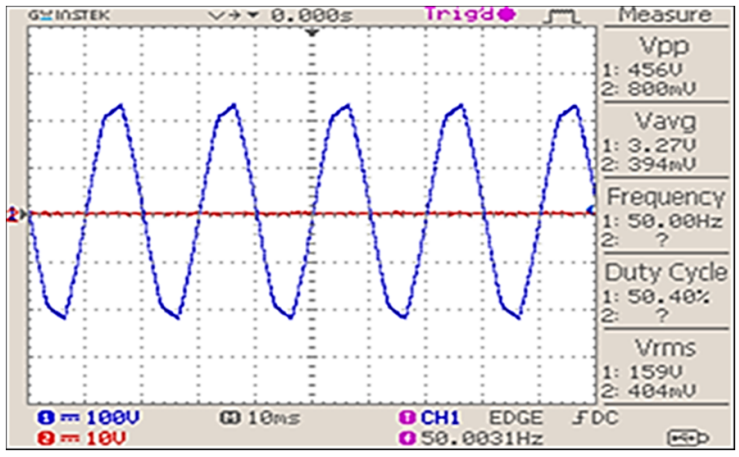

(a)

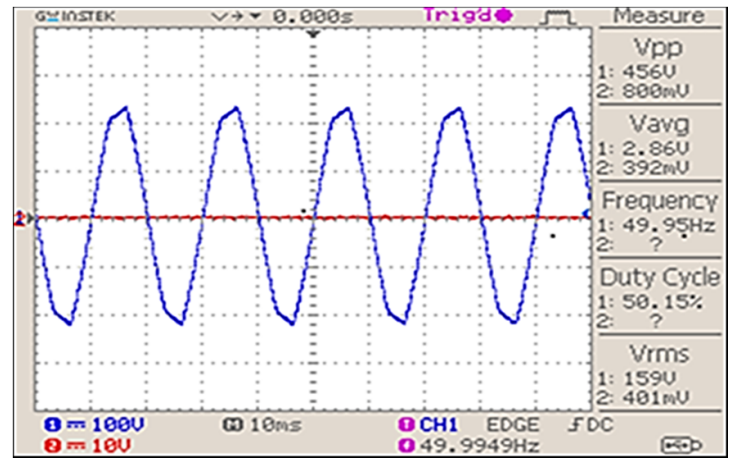

(b)

Figure 14. Grid voltage during (a) starting and (b) execution.

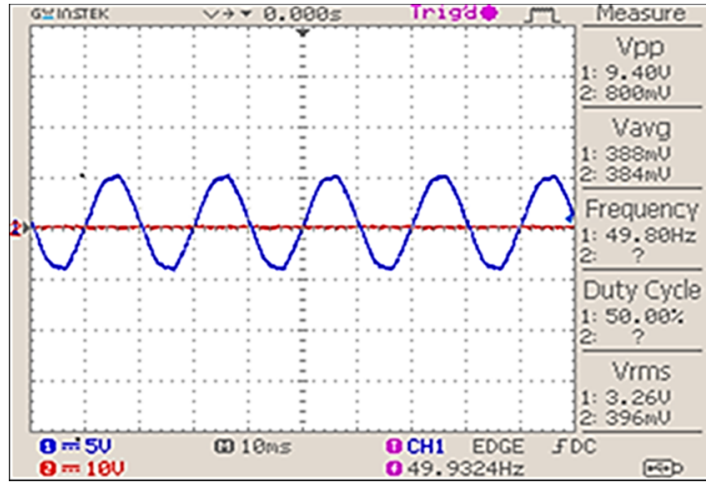

(a)

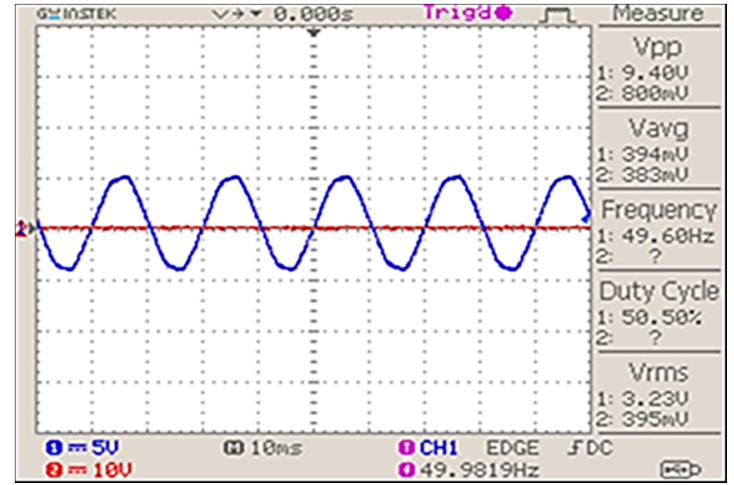

(b)

Figure 15. Grid current during (a) starting and (b) execution.

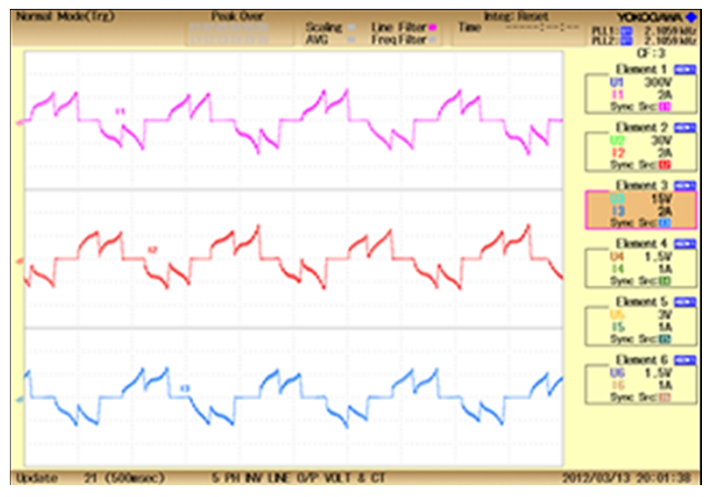

(a)

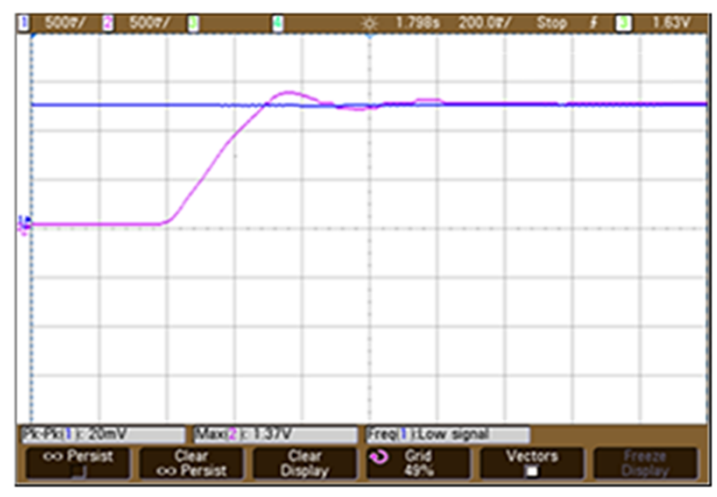

(b)

Figure 16. The brushless motor (a) current and (b) speed waveform.

Figure 17 shows the spectrum analyzer output, which contains a fundamental component of the grid current, and most of the odd harmonics are eliminated. The difference in THD value for simulation and experiment results is due to the ideal and practical nature of the components. Finally, the THD value is evaluated, and it is found to be $3.9 \%$. 


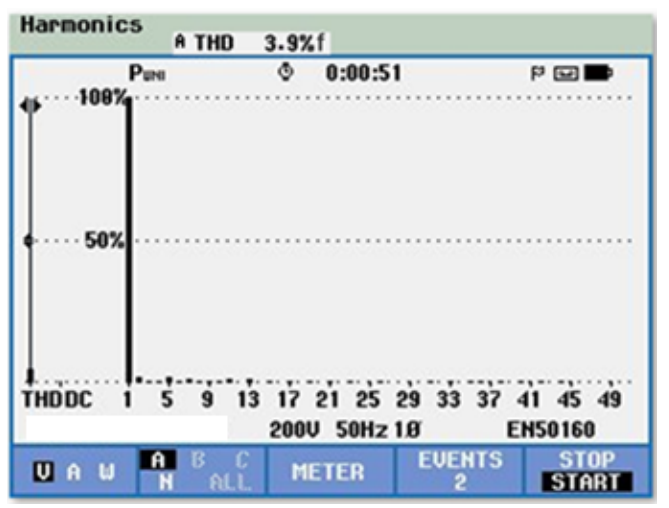

Figure 17. Grid current total harmonic distortion (THD).

Thus, with the optimized PI controller, the THD is minimized well below the Institute of Electrical and Electronics Engineers (IEEE) standard, which ensures the suitability and stability of the proposed work in BLDC fed water pumping applications. The detailed comparison of THD in both simulation and experimental is shown in Table 4. The system can deliver continuous power to the motor both at the day and night time from the PV and grid. In addition, even in the day time, if the PV output is negligibly small, the system extracts power from the grid and fed to the motor.

Table 4. Grid current THD and power factor comparison.

\begin{tabular}{ccccc}
\hline Converter & $\begin{array}{c}\text { THD with PI } \\
\text { Controller }\end{array}$ & $\begin{array}{c}\text { PF with PI } \\
\text { Controller }\end{array}$ & $\begin{array}{c}\text { THD with Whale } \\
\text { Optimized PI Controller }\end{array}$ & $\begin{array}{c}\text { PF with Whale } \\
\text { Optimized PI Controller }\end{array}$ \\
\hline PI Luo (Simulation) & 4.2 & 0.97 & 2.9 & 0.989 \\
PI Luo (Hardware) & 4.5 & 0.965 & 3.9 & 0.986 \\
\hline
\end{tabular}

\section{Conclusions}

The functioning of the proposed optimally tuned I-Luo converter for PV array fed BLDC motor-driven centrifugal pump has been clearly tested in the matrix laboratory (MATLAB), version 2018a. The simulation result of this proposed work ensures that the flow rate of the pump has been exaggerated and maintained in a steady-state mode even if the atmospheric condition and irradiation have been varied.

In order to improve the overall performance of the proposed work, a whale optimization-based control strategy has been adopted. This control system regulates the output of the I-Luo converter by changing the duty cycle of the PWM pulses. The modeling and design of the whale optimized PI controller for the I-Luo converter are accomplished to verify the performance of the BLDC motor during the steady-state and dynamic operation. The elimination of oscillation in DC-link voltage, grid current, and voltage, extraction of MPP in PV, reduced minimum loss in the switching of inverters, efficient speed control with reduced cost are the objective functions of the optimized PI controller. In addition, the current injected into the grid has a THD of $3.9 \%$ with experimentation and $2.9 \%$ in a simulation that satisfies the IEEE standard. In addition, the retrieved output validates that the overall operation and efficiency of the proposed system have been enhanced, which confirms the effectiveness of the whale optimized PI control technique.

Thus, by making use of the proposed optimally tuned controller, the problem of maximum peak shoot is surmounted, and at the same time, switching losses are reduced, making the overall WPS operation resilient. 
Author Contributions: Conceptualization, A.D.G.J., M.S.P.S., and N.M.K.; data curation, A.D.G.J., M.S.P.S., and N.M.K.; formal analysis, A.D.G.J., M.S.P.S., and N.M.K.; funding; A.G.; methodology, A.D.G.J., M.S.P.S., and N.M.K.; resources, M.S.P.S., and N.M.K.; supervision, M.S.P.S.; visualization, A.D.G.J., and N.M.K.; writing—original draft, A.D.G.J., and N.M.K., writing-review and editing, M.S.P.S., N.M.K., and A.G. All authors have read and agreed to the published version of the manuscript.

Funding: This research activity received no external funding.

Conflicts of Interest: The authors declare no conflict of interest.

\section{Appendix A}

Appendix A.1. Design of Interleaved LUO Converter

The inductor $L_{1}, L_{2}$ in the I-Luo converter is calculated by using Equation (A1);

$$
\begin{gathered}
L_{1}, L_{2}=\frac{V_{p v}(\min )}{\Delta I_{L} \cdot f_{s w}} \cdot d m a x \\
L_{1}, L_{2}=0.273 \mathrm{mH}
\end{gathered}
$$

Equation (A2) calculates the capacitors $C_{1}, C_{2}$ in the I-Luo converter;

$$
\begin{gathered}
C_{1}=I_{0} \times d \max / \Delta V_{c} f_{s w} \\
C_{1}, C_{2}=486 \mathrm{nF}
\end{gathered}
$$

The resultant capacitance value can be obtained by using Equation (A3);

$$
\begin{aligned}
& C_{o}=\frac{I_{0} . d}{V_{\text {ripple }} X_{0.5} X_{f s w}} \\
& C_{0}=1105.27 \mu \mathrm{F}
\end{aligned}
$$

\section{Appendix A.2. Comparison of Voltage Gains of Different Interleaved Converters}

Figure A1 shows the voltage gain comparison of different interleaved converters, which indicates that the voltage transfer ratio is linearly varying with the duty cycle. The conversion ratio attains the peak value with a $100 \%$ duty cycle. The conversion ratio of the proposed converter positive I-Luo (P.I.LUO) is nearly three, and that for positive Interleaved SEPIC (P.I.SEPIC), and positive Interleaved Boost (P.I.BOOST) are two and 1.5 for a $50 \%$ duty cycle. As the duty cycle is increased, the switching losses also increase; thereby, the overall performance of the system is degraded.

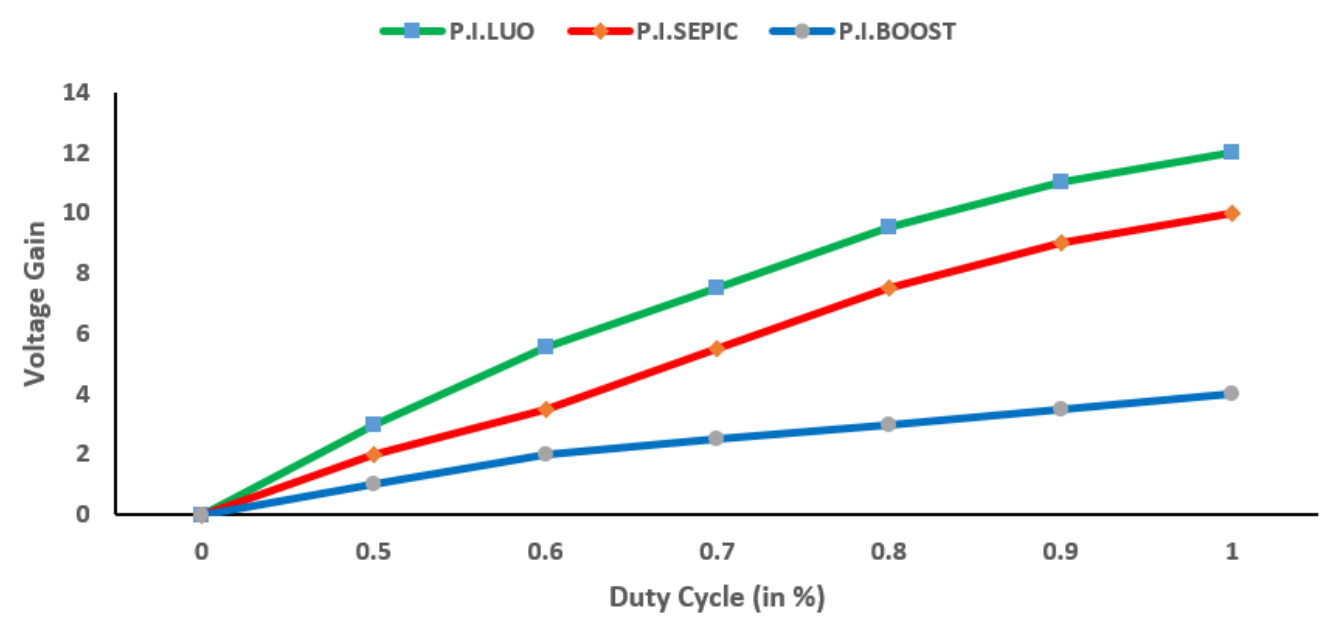

Figure A1. Comparison of voltage gains of different interleaved converters. 
Appendix A.3. Efficiency Comparison of Converters

Figure A2 shown below compares the efficiencies of positive Interleaved Luo, SEPIC, and boost converters. With a maximum of $97 \%$ efficiency, the proposed I-Luo converter outperforms the Interleaved SEPIC and boost converters whose efficiencies are $82 \%$ and $90 \%$, respectively.

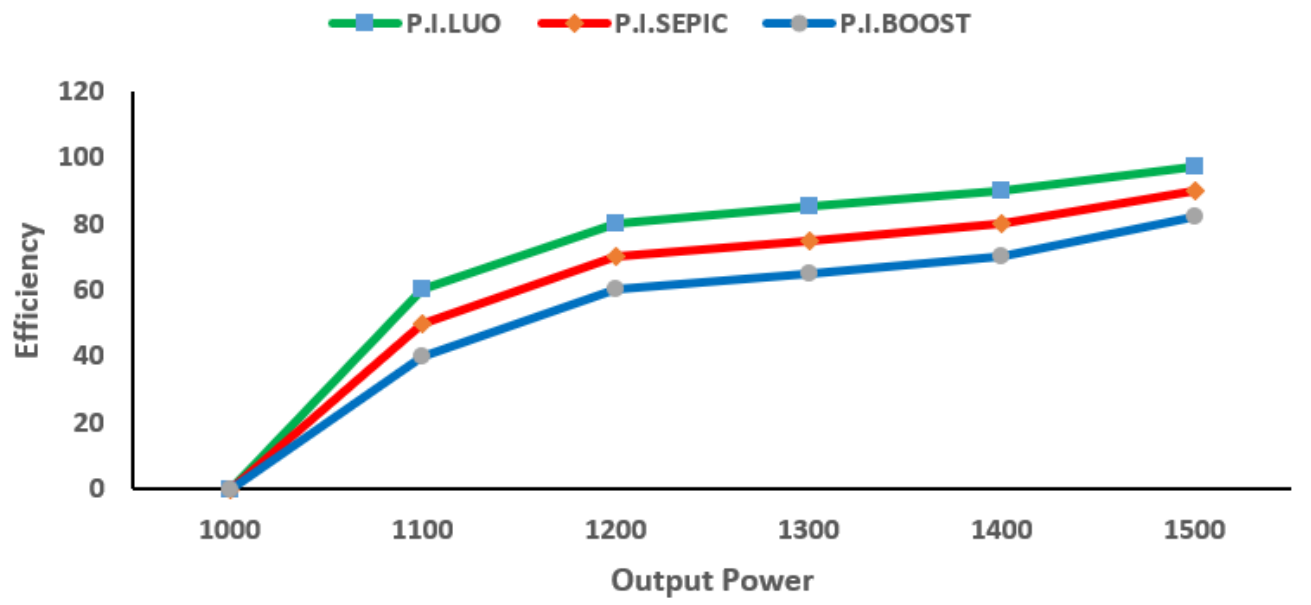

Figure A2. Efficiency comparison of different converters with the optimized controller.

The proposed (I-Luo) converter shows the different performance when the conventional PI controller is replaced with the whale optimized (WO) PI controller. As shown in Figure A3, when the output power increases from the minimum value to the maximum expected value, the efficiency also increases gradually. Thus, it is proved that the converter performance is enhanced with an optimized controller. Even if the output power is increased above 1500, the efficiency of Whale optimization algorithm (WOA) is superior to the PI controller and reaches a maximum of $100 \%$ efficiency.

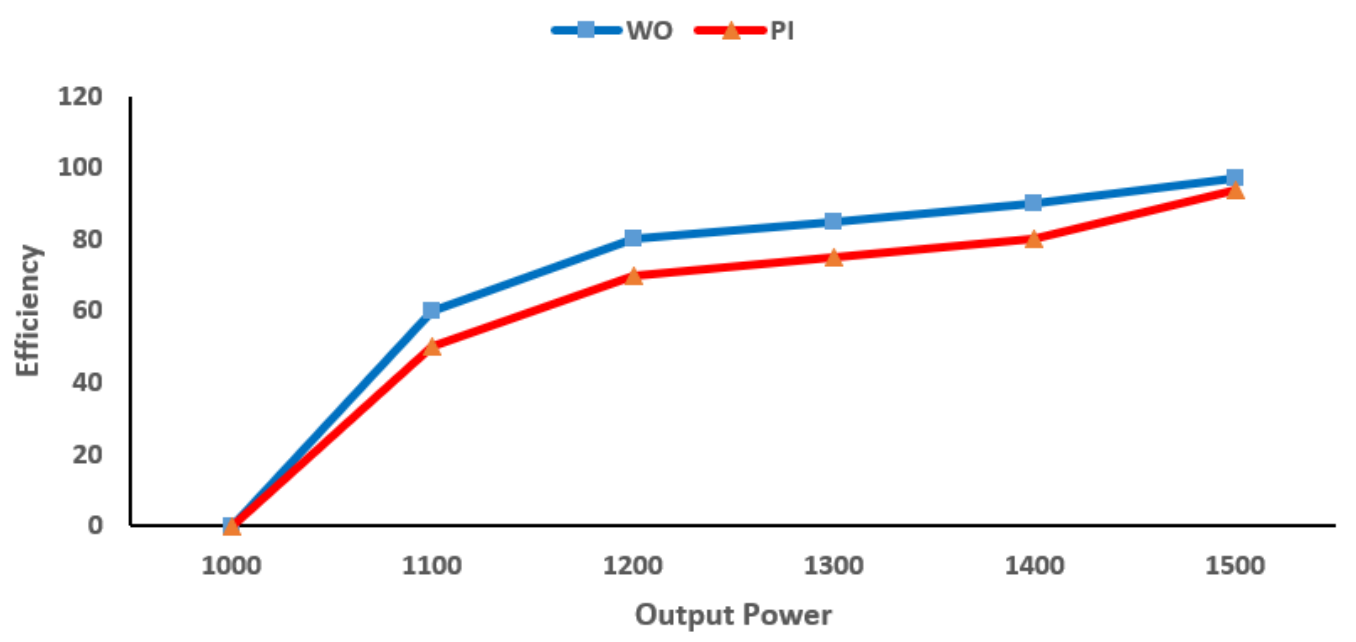

Figure A3. Comparison of conventional and optimized proportional-integral controllers of the proposed converter.

\section{Appendix A.4. Brief Theory of Whale Optimization Algorithm}

Whales are extravagant animals and are treated as the greatest warm-blooded creatures on the planet and are generally considered as a predator. They never take rest since they need to inhale from the outside of the sea. Indeed, half of the cerebrum is involved in sleep. The fascinating thing about them is that they are profoundly insightful creatures with feelings. They have basic cells in specific territories of their cerebrums called axle cells, similar to humans. With these cells, they make 
judgments, feel, and behave socially with people. It has been demonstrated that they can think, learn, judge, impart, and become passionate as we do, however, with a much lower level of savvy [26]. It is seen that whales (executioner whales) can build up their own tongue also. The most intriguing thing about the humpback whales is their unique chasing strategy. This rummaging conduct is called a bubble-net caring strategy. Humpback whales chase little fishes near to its surface. It has been seen that this scrounging is finished by making particular air pockets along a circle. This conduct was explored using the perception of the surface. Scientists have explored this conduct using label sensors. They caught 200 inferred bubble-net caring occasions of nine individual humpback whales. They discovered two-moves related to bubble and named them 'upward-spirals' and 'twofold circles.' In the previous move, humpback whales plunge around $15 \mathrm{~m}$ down and afterward begin to make bubbles in a winding shape around the prey and swim up toward the surface. The later move incorporates three unique stages: coral circle, lobtail, and catch circle. It is referenced that bubble-net caring is interesting to conduct that must be seen in humpback whales [28,29].

\section{References}

1. Chopra, S.S.; Khanna, V. Interconnectedness and interdependencies of critical infrastructures in the US economy: Implications for resilience. Phys. A Stat. Mech. Appl. 2015, 436, 865-877. [CrossRef]

2. Siddiqi, A.; Wescoat, J.L., Jr. Energy use in large-scale irrigated agriculture in the Punjab province of Pakistan. Water Int. 2013, 38, 571-586. [CrossRef]

3. Cota, O.D.; Kumar, N.M. Solar energy: A solution for street lighting and water pumping in rural areas of Nigeria. In Proceedings of the International Conference on Modelling, Simulation and Control (ICMSC-2015), Coimbatore, India, 15-16 October 2015; pp. 1073-1077.

4. Kumar, R.; Singh, B. Single stage solar PV fed brushless DC motor driven water pump. IEEE J. Emerg. Sel. Top. Power Electron. 2017, 5, 1377-1385. [CrossRef]

5. Kumar, R.; Singh, B. Grid interactive solar PV-based water pumping using BLDC motor drive. IEEE Trans. Ind. Appl. 2019, 55, 5153-5165. [CrossRef]

6. Youssef, M.Z. Design and performance of a cost-effective BLDC drive for water pump application. IEEE Trans. Ind. Electron. 2014, 62, 3277-3284. [CrossRef]

7. Shukla, S.; Singh, B. Reduced current sensor based solar PV fed motion sensorless induction motor drive for water pumping. IEEE Trans. Ind. Inform. 2018, 15, 3973-3986. [CrossRef]

8. Manoj Kumar, N.; Ghosh, A.; Chopra, S.S. Power Resilience Enhancement of a Residential Electricity User Using Photovoltaics and a Battery Energy Storage System under Uncertainty Conditions. Energies 2020, 13, 4193. [CrossRef]

9. Agua, O.F.B.; Basilio, R.J.A.; Pabillan, M.E.D.; Castro, M.T.; Blechinger, P.; Ocon, J.D. Decentralized versus Clustered Microgrids: An Energy Systems Study for Reliable Off-Grid Electrification of Small Islands. Energies 2020, 13, 4454. [CrossRef]

10. Faraji, J.; Babaei, M.; Bayati, N.; Hejazi, M.A. A comparative study between traditional backup generator systems and renewable energy based microgrids for power resilience enhancement of a local clinic. Electronics 2019, 8, 1485. [CrossRef]

11. Murshid, S.; Singh, B. Utility Grid Interfaced Solar WPS Using PMSM Drive With Improved Power Quality Performance for Operation under Abnormal Grid Conditions. IEEE Trans. Ind. Appl. 2019, 56, 1052-1061. [CrossRef]

12. Errouissi, R.; Al-Durra, A.; Muyeen, S.M. Experimental validation of a novel PI speed controller for AC motor drives with improved transient performances. IEEE Trans. Control Syst. Technol. 2017, 26, 1414-1421. [CrossRef]

13. Chincholkar, S.H.; Chan, C.Y. Comparative study of current-mode controllers for the positive output elementary Luo converter via state-space and frequency response approaches. IET Power Electron. 2015, 8 , 1137-1145. [CrossRef]

14. Tey, K.S.; Mekhilef, S. Modified incremental conductance algorithm for photovoltaic system under partial shading conditions and load variation. IEEE Trans. Ind. Electron. 2014, 61, 5384-5392. 
15. Killi, M.; Samanta, S. Modified perturb and observe MPPT algorithm for drift avoidance in photovoltaic systems. IEEE Trans. Ind. Electron. 2015, 62, 5549-5559. [CrossRef]

16. Darcy Gnana Jegha, A.; Subathra MS, P.; Manoj Kumar, N.; Subramaniam, U.; Padmanaban, S. A High Gain DC-DC Converter with Grey Wolf Optimizer Based MPPT Algorithm for PV Fed BLDC Motor Drive. Appl. Sci. 2020, 10, 2797. [CrossRef]

17. Singh, B.; Bist, V. A BL-CSC converter-fed BLDC motor drive with power factor correction. IEEE Trans. Ind. Electron. 2014, 62, 172-183. [CrossRef]

18. Dai, Y.X.; Wang, H.; Zeng, G.Q. Double closed-loop PI control of three-phase inverters by binary-coded extremal optimization. IEEE Access 2016, 4, 7621-7632. [CrossRef]

19. Ambia, M.N.; Hasanien, H.M.; Al-Durra, A.; Muyeen, S.M. Harmony search algorithm-based controller parameters optimization for a distributed-generation system. IEEE Trans. Power Deliv. 2015, 30, 246-255.

20. Khorramabadi, S.S.; Bakhshai, A. Critic-based self-tuning PI structure for active and reactive power control of VSCs in microgrid systems. IEEE Trans. Smart Grid 2014, 6, 92-103. [CrossRef]

21. Freijedo, F.D.; Vidal, A.; Yepes, A.G.; Guerrero, J.M.; Lopez, O.; Malvar, J.; Doval-Gandoy, J. Tuning of synchronous-frame PI current controllers in grid-connected converters operating at a low sampling rate by MIMO root locus. IEEE Trans. Ind. Electron. 2015, 62, 5006-5017. [CrossRef]

22. Bist, V.; Singh, B. An adjustable-speed PFC bridgeless buck-boost converter-fed BLDC motor drive. IEEE Trans. Ind. Electron. 2013, 61, 2665-2677. [CrossRef]

23. Siddharthan, N.; Balasubramanian, B. Performance evaluation of SEPIC, Luo and ZETA converter. Int. J. Power Electron. Drive Syst. 2019, 10, 374. [CrossRef]

24. Zhou, X.; Chen, X.; Lu, M.; Zeng, F. Rapid self-compensation method of commutation phase error for low-inductance BLDC motor. IEEE Trans. Ind. Inform. 2017, 13, 1833-1842. [CrossRef]

25. Babu, T.S.; Yousri, D.; Balasubramanian, K. Photovoltaic array reconfiguration system for maximizing the harvested power using population-based algorithms. IEEE Access 2020, 8, 109608-109624. [CrossRef]

26. Elbaksawi, O. Whale Optimization Algorithm for Maximum Power Point Tracker for Controlling Induction Motor Driven by Photovoltaic System. WSEAS Trans. Power Syst. 2019, 14, 70-78.

27. Zhou, Y.; Zhang, D.; Chen, X.; Lin, Q. Sensorless direct torque control for saliency permanent magnet brushless DC motors. IEEE Trans. Energy Convers. 2015, 31, 446-454. [CrossRef]

28. Ezzeldin, R.M.; Djebedjian, B. Optimal design of water distribution networks using whale optimization algorithm. Urban Water J. 2020, 17, 14-22. [CrossRef]

29. Tian, T.; Zhao, W.; Zhen, W.; Liu, C. Application of Improved Whale Optimization Algorithm in Parameter Identification of Hydraulic Turbine at No-Load. Arab. J. Sci. Eng. 2020. [CrossRef]

(C) 2020 by the authors. Licensee MDPI, Basel, Switzerland. This article is an open access article distributed under the terms and conditions of the Creative Commons Attribution (CC BY) license (http://creativecommons.org/licenses/by/4.0/). 